\title{
Towards machine ecoregionalization of Earth's landmass using pattern segmentation method
}

\author{
Jakub Nowosad, Tomasz F. Stepinski* \\ Space Informatics Lab, Department of Geography and GIS, University of Cincinnati, Cincinnati, USA
}

\begin{abstract}
We present and evaluate a quantitative method for delineation of ecophysigraphic regions throughout the entire terrestrial landmass. The method uses the new pattern-based segmentation technique which attempts to emulate the qualitative, weight-of-evidence approach to a delineation of ecoregions in a computer code. An ecophysiographic region is characterized by homogeneous physiography defined by the cohesiveness of patterns of four variables: land cover, soils, landforms, and climatic patterns. Homogeneous physiography is a necessary but not necessarily sufficient condition for a region to be an ecoregion, thus machine delineation of ecophysiographic regions is the first, important step toward global ecoregionalization. In this paper, we focus on the first-order approximation of the proposed method - delineation on the basis of the patterns of the land cover alone. We justify this approximation by the existence of significant spatial associations between various physiographic variables. Resulting ecophysiographic regionalization (ECOR) is shown to be more physiographically homogeneous than existing global ecoregionalizations (Terrestrial Ecoregions of the World (TEW) and Bailey's Ecoregions of the Continents (BEC)). The presented quantitative method has an advantage of being transparent and objective. It can be verified, easily updated, modified and customized for specific applications. Each region in ECOR contains detailed, SQL-searchable information about physiographic patterns within it. It also has a computergenerated label. To give a sense of how ECOR compares to TEW and, in the U.S., to EPA Level III ecoregions, we contrast these different delineations using two specific sites as examples. We conclude that ECOR yields regionalization somewhat similar to EPA level III ecoregions, but for the entire world, and by automatic means.
\end{abstract}

Keywords: Global ecoregions, Environmental variables, Regionalization, Segmentation, Pattern

\section{Introduction}

Terrestrial ecoregions (hereafter referred to as ecoregions) ${ }^{24}$ are the result of regionalization of land into areal units of homogeneous ecosystem which contrast from surroundings. Be- ${ }^{26}$ cause the means of such regionalization are not the part of their ${ }^{27}$ definition, ecoregions are an umbrella term with a clear gen- ${ }^{28}$ eral intent, but with specifics depending on how ecosystems ${ }^{29}$ are described and compared (Gonzales, 1966; Jax, 2006; Haber, 2011), on the spatial scale considered, and on the approach to the regionalization procedure.

The need for ecoregions was initially driven by conserva- ${ }^{33}$ tion planning (Larsen et al., 1994), but their usage has since ${ }^{34}$ expanded to tabulating environmental information in general. Ecoregions are mapped at different scales from global to local. At the broadest scale regionalization of ecoregions relies on cli- ${ }^{37}$ matic, geologic, and geomorphologic divisions (Bailey, 2014). At the finer spatial scale more attention is given to landscape ${ }^{39}$ patterns, vegetation types and biodiversity, and, eventually, at the local scale, attention shifts to specific species of flora and fauna (see, for example, Blasi et al. (2014)).

Several different approaches have been applied to a delineation of ecoregions on the broad scale. Bailey $(1989,2014){ }_{45}^{44}$

\footnotetext{
${ }^{*}$ Corresponding author

Email address: stepintz@uc.edu (Tomasz F. Stepinski)
}

developed a deductive approach wherein delineation of ecoregions follows from identifying environmental variables responsible for differentiating between ecosystems and drawing boundaries where these variables change significantly. Resulting regionalization is known as Bailey's Ecoregions of the Continents (BEC). Olson et al. (2001) applied a synthetic approach wherein ecoregions are delineated based on a large body of previous biogeographical studies. Existing information was refined and synthesized using expert judgment. Resulting regionalization is referred to as Terrestrial Ecoregions of the World (TEW). The similar synthetic methodology was applied on a regional scale to develop the Digital Map of European Ecological Regions (DMEER) (Painho et al., 1996) and the Interim Biogeographic Regionalisation for Australia (IBRA) (EA, 2000). Omernik (1987) used a weight-of-evidence approach to delineate ecoregions in the conterminous U.S. In this approach maps of environmental variables are overlaid and ecoregions are delineated by expert judgment through reconciling differences between variability of individual variables. The difference between Bailey's deductive approach and the weight-of-evidence approach is that whereas in the first the reconciliation follows an a priori determined scheme while in the second it is done on the case-by-case basis.

The issue with the synthetic approach to ecoregionalization (TEW, DMEER, IBRA) lies in the lack of quantitative frame- 
work. TEW is a compilation of local regions taken from pre-105 existing, independently conducted studies. On one hand, this ${ }_{106}$ may be viewed as a positive because TEW combines expert ${ }_{10}$ knowledge of the broad community. On the other hand, there ${ }_{108}$ are no straightforward means to inspect materials and protocols 109 that contributed to the creation of TEW. As there is no under-110 lying quantitative framework, there are no quantitative criteria 111 to assess the quality of TEW. Therefore, no systematic checks, 112 modifications or objective updates to TEW are possible. More-113 over, although many individual regions in TEW may be well-114 delineated, as a whole, TEW lacks overall consistency. A user ${ }_{115}$ has no means of knowing which regions are well-delineated ${ }_{116}$ and which are not. TEW legend conveys a short description ${ }_{117}$ of a region which usually pertains to a combination of region's ${ }_{118}$ geography, climate, and flora. Because regions in TEW lack l19 $_{19}$ quantitative description, the inter-regions comparison is limited $_{120}$ to contrasting their short descriptions in the legend.

The weight-of-evidence approach (Omernik, 1987; Omernik 122 and Griffith, 2014) also lacks quantitative framework, but, it is 123 rooted in a clear conceptual framework - "Ecoregions should 124 depict areas of similarity in the collective patterns of all biotic, 125 abiotic, terrestrial, and aquatic ecosystem components with hu-126 mans being part of the biota." (Omernik and Griffith, 2014). ${ }_{127}$ Regions are delineated manually by experts on the basis of vi-128 sually perceived breaks in aforementioned patterns. In this ap- 129 proach the resulting ecoregionalization may be consistently de-130 lineated (to a degree that humans perception can be consistent), ${ }_{131}$ but, like in the case of TEW, a user has no means of determin-132 ing the quality of the regionalization. Omernik's legend has the ${ }_{133}$ character similar to that in TEW, the inter-regions comparison ${ }_{134}$ is limited to contrasting their descriptions in the legend.

In BEC a delineation of regions follows the Köppen-136 Trewartha climate classification modified by land cover infor- ${ }^{-137}$ mation (Bailey, 2014). BEC legend conveys regions' climatic ${ }_{138}$ and floristic character. Because of its reliance on the climate, ${ }_{139}$ BEC offers only the broadest scale regionalization.

An attempt to automate the ecoregionalization process using a multivariate $k$-means clustering algorithm was made by Hargrove and Hoffman (2005) and followed up by Kumar et al.141 (2011). In such framework vectors of environmental variables ${ }_{142}$ are associated with each pixel (a tract of land corresponding to 143 the resolution of the data) and pixels agglomerated into larger ${ }_{144}$ zones (ecoregions) on the basis of the Euclidean distance be-145 tween these vectors. Such automated approach addresses issues 146 related to objectivity, consistency, and inter-region comparabil-147 ity (see our discussion above), however, its ability to yield a $a_{148}$ useful ecoregionalization is limited by the choice of clustering ${ }_{149}$ as a technique enabling the automation. Clustering leads to $\mathrm{a}_{150}$ delineation of non-contiguous, highly fragmented zones, with ${ }_{151}$ the fragments spread over wide areas. Clustering may be well-152 suited for classification but it is ill-suited for mapping. Mapping ${ }_{153}$ needs to be based on characteristics which are macroscopically ${ }_{154}$ recognizable (Klijn et al., 1995), which environmental variables 155 measured on the scale of an individual pixel are not.

In this paper, we propose and describe an approach to data-157 driven machine regionalization of the entire terrestrial landmass 158 capable of producing a useful global map of ecophysiographic ${ }_{159}$ regions. We call the resultant regions "ecophysiographic" because they are mapped based on physiography but aim at delineating ecosystems as well. This is consistent with the notion that ecoregionalization on larger scales should be based on physiography (Klijn et al., 1995; Sayre et al., 2014). Following Omernik and Griffith (2014), our mapping is based on macroscopically recognizable patterns of physiographic categorical variables, but a decision on where to put boundaries between the regions is made by a segmentation algorithm instead of a committee of experts. Segmentation is a natural choice for machine delineation of regions because it is an algorithmic implementation of regionalization. Quantitative assessment of segmentation quality corresponds directly to the qualitative notion (McMahon et al., 2001; Loveland and Merchant, 2004; Omernik and Griffith, 2014) that regions should be internally as homogeneous as possible with respect to the environment, and they should stand out from adjacent regions.

Pattern-based segmentation is the enabling technology behind our proposed method but it also presents a big challenge. This recently developed technology (Jasiewicz et al., 2015, 2017) works at present only with patterns of a single variable, not with patterns of multiple variables as our proposed framework calls for. However, we find a high level of spatial association between categories of various physiographic variables, thus we can achieve a viable regionalization by segmenting the landmass on the basis of patterns of the land cover alone. The quality of such approximation is checked a posteriori.

The goals of this paper are as follows. (1) To describe how pattern-based segmentation technique can be used for automatic creation of a global map and the legend of ecophysiographic regions. (2) To demonstrate that a segmentation based only on patterns of land cover yields a viable ecoregionalization. (3) To compare such ecoregionalization with TEW. (4) To provide a spatial database of delineated regions with a detailed quantitative description of patterns in each region.

\section{Data and Methods}

Table 1 lists four global physiographic datasets we used to calculate associations between categories of land cover, climate, topography, and soils, and to calculate homogeneity of delineated regions. Our choice of environmental variables is very similar to that made by Sayre et al. (2014) except we use newly available (Hengl et al., 2017) soil types data (reclassified to 12 orders) instead of lithology used by Sayre et al. (2014) as a proxy for soils. We also use the newest global land cover dataset - the European Space Agency (ESA) Climate Change Initiative (CCI) global land cover map (thereafter referred to as CCI-LC). Note that all variables are categorical. Land cover is arguably the most ecologically important of the four variables because it was demonstrated to provide the first-order information about geographical distribution of biodiversity and ecological processes (Siriwardena et al., 2000; Maes et al., 2003; Eyre et al., 2004; Heikkinen et al., 2004; Fuller et al., 2005; Luoto et al., 2006). Details about the CCI-LC land cover dataset including its accuracy can be found in the Land Cover CCI Product User Guide V.2 (ESA, 2017). 
Table 1: Global environmental datasets

\begin{tabular}{|l|l|l|l|l|}
\hline Variable & Dataset & Data type & Res. & Source \\
\hline land cover & CCI-LC 2010 & categorical grid (22 classes) & $300 \mathrm{~m}$ & http://maps.elie.ucl.ac.be/CCI \\
climate & $\begin{array}{l}\text { bioclimatic } \\
\text { classification } \\
\text { topography }\end{array}$ & $\begin{array}{l}\text { landforms } \\
\text { classification }\end{array}$ & $\begin{array}{l}\text { Sayre et al. (2014) modified } \\
\text { from Metzger et al. (2013) }\end{array}$ \\
soil & $\begin{array}{l}\text { SoilGrids } \\
\text { soil classification }\end{array}$ & categorical grid (17 classes) & $250 \mathrm{~m}$ & Karagulle et al. (2017) \\
\hline
\end{tabular}

\subsection{Pattern-based segmentation of Earth's landmass}

Segmentation was performed using the Geospatial Pattern ${ }_{203}^{203}$ Analysis Toolbox (GeoPAT) (Jasiewicz et al., 2015, 2017) $-\mathrm{a}_{205}$ collection of GRASS GIS (GRASS Development Team, 2016) modules for carrying out pattern-based analysis of large cate- ${ }_{207}$ gorical grids. Pattern-based segmentation differs from the standard pixel-based segmentation by agglomerating sites (tracts of ${ }_{209}$ land much larger than an individual pixel) on the basis of pat- ${ }_{210}$ terns of variable rather than agglomerating pixels on the basis of at-pixel values and texture of variables.

Fig. 1 illustrates the basic concept of the pattern-based segmentation algorithm. First, the landmass is tessellated into sites ${ }_{213}$ - square blocks (of the size $k \times k$ of CCI-LC cells) to form $\mathrm{a}_{214}$ new, $k^{2}$ coarser, grid of sites (Fig. 1A) Sites are tracts of land ${ }_{215}$ large enough to encompass patterns of physiographic variables ${ }_{216}$ but small enough to be building blocks of regions. Sites of size 217 $k=100(30 \mathrm{~km})$ are shown in Fig. 1A. A site holds a local ${ }_{218}$ pattern (mosaics of pixels assigned different land cover cate-219 gories); a pattern of the land cover in a selected site is shown ${ }_{220}$ in Fig. 1B. Those patterns are numerically described using $\mathrm{a}_{221}$ co-occurrence histogram (Jasiewicz et al., 2015; Niesterowicz 222 et al., 2016). Co-occurrence histogram encapsulates composition and configuration of the pattern. A level of dissimilarity 224 between two sites is a dissimilarity between their correspond- ${ }_{225}$ ing co-occurrence histograms and is measured by the Jensen-226 Shannon divergence (Lin, 1991). For more details on the con- ${ }_{227}$ cept of pattern-based segmentation see Supplement S2 as well ${ }_{228}$ as Niesterowicz et al. (2016) and Niesterowicz and Stepinski $i_{229}$ (2017). The number of segments and thus a character of region- 230 alization depend on parameters of the segmentation algorithm.231 Here we use a default set of parameters derived in Jasiewicz $z_{232}$ et al. (2017). The size $(k)$ of individual sites relates to the ${ }_{233}$ level of physiographic pattern generalization, larger values of ${ }_{234}$ $k$ leads to a smaller number of segments. We segmented terres- ${ }_{235}$ trial landmass assuming three different site's sizes: $k=30\left(9_{236}\right.$ $\mathrm{km}), k=50(15 \mathrm{~km})$, and $k=100(30 \mathrm{~km})$. The smallest cho- ${ }_{237}$ sen size is dictated by a requirement of having enough pixels in $_{238}$ a site to form a meaningful pattern, and the largest chosen size $_{239}$ is dictated by a desire for not having over-generalized patterns. ${ }_{240}$ We refer to resulting regionalizations as ecophysiographic re-241 gionalizations (ECORs).

Our pattern-based segmentation algorithm is based on the ${ }_{243}$ concept of seeded region growing (Fig.1C). A segment starts from a single site and grows by adding sites from its current perimeter until growth stopping criterion is met; for details see Jasiewicz et al. (2017). The end result of the segmentation is the landmass divided into regions of cohesive land cover patterns (Fig.1D). We also expect that due to the high level of association between categories of land cover and the categories of the remaining variables (see section 3.1) these regions have cohesive patterns of the remaining variables as well. Calculating quality metrics of obtained regionalization will be able to confirm or confute this expectation.

\subsection{Assessing the quality of ecoregionalizations}

Ecoregions should be characterized by homogeneous patterns of physiographic variables (Klijn et al., 1995; Sayre et al., 2014; Omernik and Griffith, 2014). In addition, it is desirable that patterns of physiographic variables in adjacent regions differ from each other. We assess a degree to which these conditions are met by ECORs using statistics of regions homogeneity and isolation metrics with respect to patterns of all physiographic variables. These statistics are calculated over all ECOR's segments. We compare ECOR-derived statistics with analogous statistics calculated over all land units in BEC, and TEW. Note that in BEC and TEW land units are individual polygons (land units) in their respective shapefiles. The term "ecoregion" in BEC and TEW does not refer to a contiguous land unit, instead it refers to a class of such units. There are 96 ecoregions containing 623 land units in BEC, and there are 825 ecoregions containing 14,458 land units in TEW.

To assess homogeneity of a region with respect to a pattern of land cover, landforms, and soils we calculate an inhomogeneity metric. Region's inhomogeneity is a mutual dissimilarity between all sites within this region. A detailed explanation of inhomogeneity metric is given in Supplement S2 or in Jasiewicz et al. (2017). Inhomogeneity of BEC regions is calculated assuming site's size of $k=100$ because of their large sizes, and inhomogeneity of TEW regions is calculated assuming site's size of $k=30$ because of their smaller sizes. Inhomogeneity metric has a range 0 to 1 , smaller values are better (they indicate larger homogeneity).

Climate changes on large spatial scales, thus climate categories do not form patterns over extents of most regions. Therefore, to assess homogeneity of a region with respect to climate 


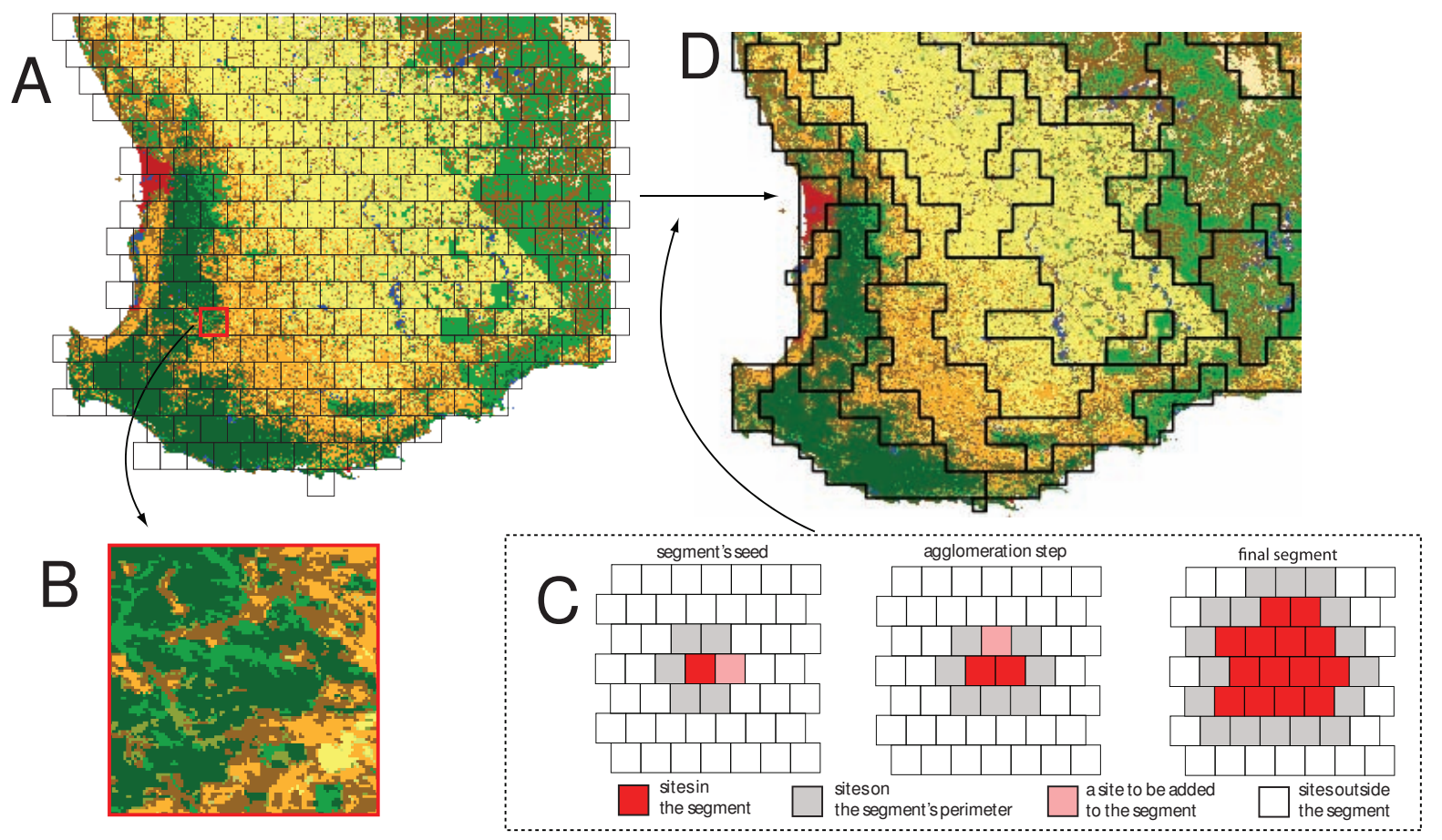

Figure 1: Basic concept of pattern-based segmentation using a fragment of landmass located in the southwestern Australia around the city of Perth. (A) A grid of sites. (B) A zoom-in onto a single $30 \mathrm{~km} \times 30 \mathrm{~km}$ site to show its pattern. (C) The concept of seeded region growing algorithm; see the main text for a description. (D) The result of the segmentation algorithm is the regionalization of land cover patterns. The background map is the CCI-LC, different colors indicate different categories of land cover (see Supplement S3 for the legend).

we calculate its Shannon's entropy, $H=-\sum_{i=1}^{m} p(i) \log _{2} p(i), 269$ where $p(i)$ is a fraction of region's area occupied by the cate-270 gory $i$ of the climate variable. The summation is over all $m=37_{271}$ categories of bioclimate (see SupplemntS3). Minimum possi-272 ble value of $H$ is zero and it occurs when a segment is com-273 pletely within a single climate category (it is completely homo-274 geneous). The larger the value of $H$ the more inhomogeneous 275 the segment is with respect to climate.

To assess how much a pattern in a given region differs from patterns in neighboring regions we calculate an isolation metric. To obtain a value of region's isolation metric we calculated an average dissimilarity (JSD) between the focus region and all of its immediate neighbors. The average is weighted by the percentage of region's perimeter shared with different neighbors. See Supplement S2 or Jasiewicz et al. (2017) for details. To calculate isolation with respect to climate, percentages of region's area occupied by different climate types are used instead of the co-occurrence histograms in the calculation of JSD. Isolation metric has a range 0 to 1 , larger values are better (regions are more distinct).

\section{Results}

\subsection{Associations between physiographic variables}

We first estimate a degree of association between our four 2 physiographic variables in order to provide a priori rationale for 280 using land cover patterns as the only input to the segmentation 281 algorithm. We want to check to what degree categories of different variables co-occur on the scale of our sites. To start we regridded the four variables from their native resolutions (see Table 1) to grids with $9 \mathrm{~km} \times 9 \mathrm{~km}$ and $30 \mathrm{~km} \times 30 \mathrm{~km}$ cells using the mode values method. Because we deal with categorical variables we use Cramér's V measure of association (Cramér, 2016). Table 2 shows the values of Cramér's V for all combinations of variables.

Table 2: Degree of association between physiographic variables
\begin{tabular}{|r|r|r|r|r|r|r|}
\hline & LC & BC & LF & S & Mean & St.Dev. \\
\hline \multicolumn{7}{|c|}{$9 \mathbf{k m} \times \mathbf{9 k m}$ sites } \\
\hline LC & n/a & 0.34 & 0.20 & 0.40 & 0.32 & 0.10 \\
BC & 0.34 & n/a & 0.13 & 0.50 & 0.32 & 0.19 \\
LF & 0.20 & 0.13 & n/a & 0.09 & 0.14 & 0.05 \\
S & 0.40 & 0.50 & 0.09 & n/a & 0.33 & 0.21 \\
\hline \multicolumn{7}{|c|}{30 km $\times \mathbf{3 0 k m ~ s i t e s ~}$} \\
\hline LC & n/a & 0.34 & 0.19 & 0.40 & 0.31 & 0.11 \\
BC & 0.34 & n/a & 0.13 & 0.51 & 0.33 & 0.19 \\
LF & 0.19 & 0.13 & n/a & 0.1 & 0.14 & 0.05 \\
S & 0.40 & 0.51 & 0.1 & n/a & 0.34 & 0.21 \\
\hline
\end{tabular}

Our results in Table 2 indicate that mutual associations between land cover, soils and climate are higher $(0.3-0.5)$ than association of these variables with landforms $(0.09-0.2)$. According to one interpretation (Corbett and LeRoy, 2003) of Cramér's $\mathrm{V}$ values $\mathrm{V}<0.2$ indicates a weak association, $\mathrm{V}=$ 
$0.2-0.25$ indicates a moderate relationship, $\mathrm{V}=0.25-0.30$ indicates a moderately strong association, and $\mathrm{V}>0.3$ indicates a strong association. Using this interpretation, values in Table 2 indicate three physiographic variables, land cover, soils, and bioclimate to be strongly mutually associated. The landforms variable is only weakly associated with the remaining three variables, but most associated with the land cover. Thus, an association analysis reveals that land cover is the best choice of the variable to be used as a sole input to the segmentation algorithm. A priori analysis suggests that obtained regions should be homogeneous with respect to land cover, soils, and climate, but maybe less homogeneous with respect to landforms.

\subsection{Regionalizations}

ECORs based on $30 \mathrm{~km} \times 30 \mathrm{~km}$ sites, $15 \mathrm{~km} \times 15 \mathrm{~km}$ sites, and $9 \mathrm{~km} \times 9 \mathrm{~km}$ sites yield 9,942, 36,284, and 101,274 regions, respectively. Areas of regions vary greatly from as little as the size of a single site to as much as $1.2 \times 10^{7} \mathrm{~km}^{2}$. Those ecoregionalizations are in the form of SQL-searchable spatial ${ }^{33}$ databases. The list of attributes for each region includes an ID $^{338}$ number, region's area, the physiography (the area shares of land ${ }^{339}$ cover, bioclimate, landforms, and soils categories), values of ${ }^{340}$ inhomogeneity and isolation metrics, and the numerical code ${ }^{341}$ which encapsulates a short overall description of a region. The ${ }^{342}$ shares of categories provide a detailed numerical description ${ }^{343}$ of physiography in each region. A database could be used to ${ }^{344}$ search for regions which are similar to each other on the basis ${ }^{345}$ of any combinations of categories.

The numerical code gives an information about a region's ${ }^{347}$ physiography compressed to a single, 16-digit number; the list ${ }^{348}$ of deciphered codes form a legend to the ECOR map. To ${ }^{349}$ make such a compact representation possible we first analyzed ${ }^{350}$ statistics of regions' categories shares (histograms of categories ${ }^{351}$ present in a region). It turns out that for all four variables, ${ }^{352}$ histograms are either predominantly monothematic or predom- ${ }^{353}$ inantly bi-thematic.

Table 3 shows data in support of this finding. The entries in ${ }^{355}$ the table are (percentage of all regions in a given type of histogram (monothematic or bi-thematic) / average percentage of ${ }^{356}$ region's area in either a top category (for monothematic) or in ${ }_{357}$ top two categories (for bi-thematic). For example, the entry 358 $14 / 89$ means that $14 \%$ of regions have patterns of land cover 359 dominated (on average $89 \%$ share of region's area) by a sin-360 gle category, and the entry $86 / 79$ means that $86 \%$ of regions 361 have patterns of land cover dominated by top two categories 362 (on average $79 \%$ of such region's area is occupied by top two ${ }_{363}$ categories). Thus, a land cover in a given region can be suc-364 cinctly described by a four-digit number ABCD, where the first 365 two digits, $\mathrm{AB}$, indicate the top category (one of 22 , see Table 366 1) and the last two digits, $\mathrm{CD}$, indicate the second top category.367 If a region is monothematic $\mathrm{CD}=00$. This procedure creates 368 429 unique land cover codes in the $9 \mathrm{~km}$ sites-base regionaliza-369 tion and 357 unique land cover codes in the $30 \mathrm{~km}$ site-based ${ }_{370}$ regionalization. The same procedure is repeated for remaining ${ }_{371}$ variables, and individual four-digit numbers are combined into ${ }_{372}$ a single 16-digit number,
Table 3: Statistics of regions category histograms

\begin{tabular}{|r|r|r|r|}
\hline & monothematic & bi-thematic & \# of codes \\
\hline \multicolumn{4}{|c|}{ 9km sites-based regionalization } \\
\hline land cover & $14 / 89$ & $86 / 79$ & 429 \\
bioclimate & $74 / 98$ & $26 / 93$ & 307 \\
landforms & $38 / 96$ & $62 / 80$ & 167 \\
soils & $63 / 96$ & $37 / 91$ & 117 \\
\hline \multicolumn{4}{|r|}{ 30km sites-base regionalization } \\
\hline land cover & $13 / 90$ & $87 / 77$ & 357 \\
bioclimate & $59 / 96$ & $41 / 89$ & 256 \\
landforms & $29 / 94$ & $71 / 71$ & 111 \\
soils & $57 / 96$ & $43 / 89$ & 109 \\
\hline
\end{tabular}

See main text for explanation of the entries in the Table.

$$
\text { region's code }=\overbrace{\mathrm{ABCD}}^{\text {land cover }} \underbrace{\mathrm{EFGH}}_{\text {soils }} \overbrace{\text { IJKL }}^{\text {landforms }} \underbrace{\text { MNPR }}_{\text {bioclimate }}
$$

The semantic meaning of the code can be deciphered from the legends of the four variables (see Supplement S3). For example, the code 1207080012001920 has the following meaning: land cover dominated by the mixture of shrubland and needleleave evergreen forest, soils dominated by mollisols, landform dominated by high mountains, and climate a mixture of warm semi-dry and warm moist. There is only one region with this particular code and it contains Santa Catalina Mountains near Tucson, Arizona, U.S. There are 8251 unique 16-digit codes in the $30 \mathrm{~km}$ site-based ecoregionalization, and 23,660 unique 16-digit codes in the $9 \mathrm{~km}$ site-based ecoregionalization. Note that the number of unique existing codes is much smaller than combinatorially possible due to the high correlation between physiographic variables. On the other hand, a large number of unique codes indicates a high diversity of physiographic conditions over the landmass.

ECORs databases, as well as shapefiles for BEC and TEW containing the values of regions' inhomogeneity and isolations metrics as attributes, are available from http://sil.uc.edu.

\subsection{Quality of regionalizations}

Results of quality of regionalization calculations are summarized in Table 4. This table has three sections showing values of average inhomogeneity, average isolation, and average overall quality, respectively. Averages are calculated over all regions in the regionalization. An overall quality of delineation for a single region is defined as (1 - inhomogeneity/isolation). This metric has a 0 to 1 range with higher numbers indicating better delineation. The quality metric is not applicable to climate because climate's inhomogeneity and isolation are not measured in the same units. We calculate the standard, unweighted average (the left part of Table 4) and the area-weighted average (the right part of Table 4). Area-weighted average metrics may be better for comparison between different regionalizations due to significant differences between regions area distribution in BEC, TEW, and ECOR.

The numbers in Table 4 should be compared within a single column (for a given variable) to indicate which regionalization 
Table 4: Average inhomogeneities and isolations of segments in different regionalizations

\begin{tabular}{|c|c|c|c|c|c|c|c|c|}
\hline & \multicolumn{4}{|c|}{ Unweighted } & \multicolumn{4}{|c|}{ Area-Weighted } \\
\hline Name & BioClim & Landform & Land Cover & Soils & BioClim & Landform & Land Cover & Soils \\
\hline \multicolumn{9}{|c|}{ Average inhomogeneities } \\
\hline BEC & 1.32 & 0.43 & 0.34 & 0.28 & 1.54 & 0.40 & 0.33 & 0.28 \\
\hline TEW & 0.38 & 0.18 & 0.15 & 0.10 & 1.31 & 0.44 & 0.32 & 0.24 \\
\hline ECOR 9 & 0.37 & 0.22 & 0.13 & 0.07 & 0.81 & 0.31 & 0.08 & 0.10 \\
\hline ECOR 15 & 0.47 & 0.23 & 0.12 & 0.09 & 0.89 & 0.31 & 0.08 & 0.11 \\
\hline ECOR 30 & 0.62 & 0.22 & 0.12 & 0.10 & 1.00 & 0.27 & 0.08 & 0.11 \\
\hline \multicolumn{9}{|c|}{ Average isolations } \\
\hline$\overline{\mathrm{BEC}}$ & 0.32 & 0.56 & 0.49 & 0.41 & 0.38 & 0.51 & 0.46 & 0.40 \\
\hline TEW & 0.29 & 0.51 & 0.41 & 0.32 & 0.37 & 0.55 & 0.48 & 0.36 \\
\hline ECOR 9 & 0.12 & 0.36 & 0.29 & 0.17 & 0.24 & 0.39 & 0.25 & 0.13 \\
\hline ECOR 15 & 0.15 & 0.37 & 0.28 & 0.18 & 0.25 & 0.43 & 0.26 & 0.14 \\
\hline ECOR 30 & 0.20 & 0.36 & 0.28 & 0.21 & 0.28 & 0.37 & 0.25 & 0.19 \\
\hline \multicolumn{9}{|c|}{ Average quality } \\
\hline BEC & $\mathrm{n} / \mathrm{a}$ & 0.22 & 0.29 & 0.31 & $\mathrm{n} / \mathrm{a}$ & 0.21 & 0.34 & 0.32 \\
\hline TEW & $\mathrm{n} / \mathrm{a}$ & 0.61 & 0.60 & 0.63 & $\mathrm{n} / \mathrm{a}$ & 0.22 & 0.38 & 0.38 \\
\hline ECOR 9 & $\mathrm{n} / \mathrm{a}$ & 0.44 & 0.55 & 0.51 & $\mathrm{n} / \mathrm{a}$ & 0.29 & 0.69 & 0.47 \\
\hline ECOR 15 & $\mathrm{n} / \mathrm{a}$ & 0.41 & 0.56 & 0.49 & $\mathrm{n} / \mathrm{a}$ & 0.28 & 0.66 & 0.46 \\
\hline ECOR 30 & $\mathrm{n} / \mathrm{a}$ & 0.40 & 0.57 & 0.50 & $\mathrm{n} / \mathrm{a}$ & 0.29 & 0.61 & 0.47 \\
\hline
\end{tabular}

The best value for each variable is indicated in the bold font. $\mathrm{n} / \mathrm{a}$ - not applicable. 9, 15, and 30 in ECOR regionalizations refer to the size of a single site in $\mathrm{km}$.

has, on average, better-defined regions with respect to a given ${ }_{405}$ variable. In general, ECORs regions are more homogeneous 406 but less isolated than TEW and BEC. For the best overall char-407 acterization of regionalization, the inhomogeneity and isolation ${ }_{408}$ metrics need to be considered together; this is achieved by the 409 quality metric. According to the unweighted method, ECORs $s_{410}$ are characterized by smaller values of quality then TEW but $_{411}$ by higher values of quality than BEC. According to the area- ${ }_{412}$ weighted method, ECORs are characterized by higher values ${ }_{413}$ of quality than both TEW and BEC.

For landforms, land cover, and soils, the numbers in Table $4_{415}$ could also be compared within a row (for a given regionaliza-416 tion) to indicate, on average, a quality of a region delineation ${ }_{417}$ with respect to patterns of different physiographic variables.418 As expected, ECORs regions are best delineated with respect ${ }_{419}$ to the land cover. The value of 0.57 (unweighted quality for ${ }_{420}$ land cover in ECOR 30) can be interpreted as follows: in an ${ }_{421}$ average region, the similarity of its constituent sites with re-422 spect to patterns of land cover is 2.3 times higher than an av-423 erage similarity of land cover patterns between this region and $4_{22}$ its neighbors. Following this interpretation for patterns of soils ${ }_{425}$ and landforms yields the ratios of 2 and 1.67, respectively. This ${ }_{426}$ result is consistent with our expectations based on associations ${ }_{427}$ between physiographic variables (section 3.1).

Homogeneity of regions with respect to bioclimate requires 429 a separate discussion because it is measured by the entropy. То 430 get some intuition to the meaning of entropy values we give 431 few examples. In the region where $90 \%$ of the area has climate 432 A and $10 \%$ of the area has climate B the value of entropy is 433 0.47 . If the region is divided equally between two climates the 434 entropy value is 1 . Small regions are covered by a single cli-435 mate and have entropy values equal to 0 . All regionalizations, except the BEC, are, on average, climate-homogeneous. Average values of isolation with respect to bioclimate must be small because most regions are small and are surrounded by regions with the same climate type.

Based on results in Table 4 we conclude that our method yields a very good regionalization of land cover patterns (quality $=0.55 / 0.69$ using unweighted/area-weighted method for ECOR 9). It also yields a reasonable regionalization of the entire physiography with the average quality (calculated from land cover, soils, and landforms) equal to $0.5 / 0.48$ (using unweighted/area-weighted method for ECOR 9). For comparison, the average quality for TEW is $0.61 / 0.32$, and the average quality for BEC is $0.27 / 0.29$. Note a significant difference between the unweighted and area-weighted values of quality for TEW. This is explained by the fact that distribution of region areas in TEW is heavily skewed toward very small regions. In TEW a small number of large regions occupy almost the entire landmass, and a large number of small regions occupy a small fraction of the landmass.

In addition, we have produced maps showing geographical distributions of inhomogeneity, isolation, and quality metrics (see Supplement S1). Locations with high values on the maps of inhomogeneity identify regions where a pattern of a given variable is under-segmented. In ECOR there are no such regions on the maps for land cover, soils, and climate (as measured by entropy), but there are few regions which are undersegmented on the map of landforms. Inhomogeneity maps for TEW and BEC have more under-segmented regions. Undersegmentation is a significant issue because it indicates that physiography varies across a region putting its status as an 
ecoregion in doubt. Locations with high values on the maps 490 of isolation identify regions where a pattern of a given vari-491 able is over-segmented. Over-segmentation is a problem be-492 cause it indicates that neighboring regions have similar phys-493 iography and a single ecoregion may extent over several seg-494 ments. ECOR maps are generally over-segmented to a higher 495 degree than TEW and BEC maps. In algorithmic regionaliza-496 tions there is always a trade-off between minimizing inhomo-497 geneity of segments and maximizing isolation between different ${ }_{498}$ segments. This trade-off is set by maximizing the quality met-499 ric. Locations with high values on the maps of quality identify 500 regions with relatively low inhomogeneity and relatively high $5_{501}$ isolation. These are the location where delineation of regions502 is the most successful. Comparing quality maps in Supplement503 1 indicates that ECOR is overall a more successful ecoregion-504 alization then TEW or BEC when using physiography as the 505 criterion for the comparison.

\section{Discussion}

ECOR is the first attempt to obtain a global map of ecophys-511 iographic regions purely by means of an autonomous pattern- 512 based segmentation algorithm. Pixel-based segmentation was $_{513}$ previously used by Bisquert et al. (2015) for regionalization of $5_{514}$ France using MODIS time series imagery, but no attempt was ${ }_{515}$ made to check whether obtained segments are homogeneous in ${ }_{516}$ terms of landscapes, soils, climate, or other physiographic vari-517 ables. In section 2.1 we described our overall strategy for such $_{518}$ automatic regionalization as well as an implementation of this $5_{519}$ strategy given the present status (the single layer-based segmen-520 tation) of the enabling technology. After performing analysis ${ }_{52}$ of associations between four physiographic variables (section ${ }_{522}$ 3.1) we determined that patterns of land cover are best suited $_{523}$ for the single layer-based segmentation. Land cover is also $a_{524}$ natural choice because it can be used as a proxy for vegetation ${ }_{525}$ structure. In turn, vegetation can be used as a proxy for bi-526 otic composition (Kerr et al., 2001; Pearson et al., 2004; Luoto 527 et al., 2007; Coops et al., 2009) because it provides habitat re-528 sources for species. For these reasons, land cover is often used ${ }_{529}$ to provide the first-order information about geographical dis-530 tribution of biodiversity and ecological processes (Siriwardena 531 et al., 2000; Eyre et al., 2004; Heikkinen et al., 2004; Fuller ${ }_{532}$ et al., 2005; Luoto et al., 2006). We also found enough asso-533 ciation between all the variables to expect that the land cover-534 based regionalization may indeed be a viable ecophysiographic ${ }_{535}$ regionalization.

The key to evaluating whether ECOR is a viable ecoregion-537 alization is our criterion that the regions should, at the mini-538 mum, contain cohesive patterns of all physiographic variables539 - a quality quantitatively measured by the inhomogeneity met-540 ric. The analysis presented in section 3.3 shows that although ${ }_{541}$ ECOR does not yet fully meet patterns cohesiveness criterion, it542 meets it to the sufficient degree to be considered a viable ecore-543 gionalization. The argument for that follows from the fact that 544 ECOR meets patterns cohesiveness criterion to a higher degree ${ }_{54}$ than BEC and TEW (see Table 4 and Supplement S1), the two546 regionalizations of landmass generally accepted as ecoregianolizations.

The higher cohesiveness of patterns in ECOR follows mostly from its design and from the existence of the spatial association between categories of physiographic variables. Isolation of ECOR regions is on average smaller than for regions in BEC and TEW. The overall quality of ECOR regionalization is much higher than the quality of BEC regionalization, and comparable or higher (depending on the type of measurement) to the quality of TEW regionalization.

Fig. 2 shows a difference between TEW and ECOR using the island of Madagascar as an example. The most noticeable difference between the two regionalizations is the number of regions, 5 for TEW and 55 for ECOR. A large number of ECOR regions reflects its design - the algorithm painstakingly delineates all variations in the pattern of land cover. Closer inspection reveals that indeed each ECOR region contains a homogeneous pattern of land cover, and to a somewhat lesser degree, a homogeneous pattern of the entire physiography. In Fig. 2 we also included a portion of algorithm-generated legend for 12 out of $55 \mathrm{ECOR}$ regions. Note that this legend is quite specific as it informs on the state of each physiographic variable in the region. However, the auto-generated legend does not contain any specific information available only through on the ground inspection.

TEW delineates five ecoregions in Madagascar. Note that boundaries of TEW regions divide pretty well the climate, and two of them (humid forest and spiny thickets) are delineating patterns of land cover (although not to the same precision as ECOR), but the landforms are definitively not well divided by TEW ecoregions. The most inaccurate part of the TEW are the names of ecoregions. Four of them have "forest" or " woodland" in their names even so Madagascar lost about $80 \%$ of its original forest, and the forest is presently very scarce across the island (see the land cover map). We speculate that these names originated before the island was deforested. Such dramatic land change must have change island's ecosystems, so TEW division may not be any longer valid for the present day Madagascar. This goes to the difficulty of updating manual regionalizations.

Fig. 3 compares ECOR with the EPA Level III Ecoregions of the U.S. (Omernik, 1987; Omernik and Griffith, 2014) using the state of New Mexico as an example. Both, ECOR and EPA rely on patterns of environment for their delineation, except that ECOR delineation is algorithmic and EPA delineation is manual. Because both regionalizations follow the same underlying concept we expect a higher level of correspondence between ECOR and EPA than between ECOR and TEW.

Indeed, a clear correspondence between the two regionalizations is observed in Fig. 3A. Each EPA ecoregion is dominated by an ECOR region. The Chihuahuan Desert is dominated by a region characterized as (shrub; aridisols/mollisols; scat. low mtns./low mtns.; warm, semi-dry/cool, semi-dry). Arizona/New Mexico Mtns. is dominated by (tree NeEv; mollisols; low mtns./high mtns; cool, semi-dry/cool, moist). Arizona/New Mexico Plateaus is dominated by (shrub; entisols/aridisols, high hills/scat. low mtns.; cool, semi-dry). Southwestern Rockies are dominated by (tree NeEv; alfisols/mollisols; high 

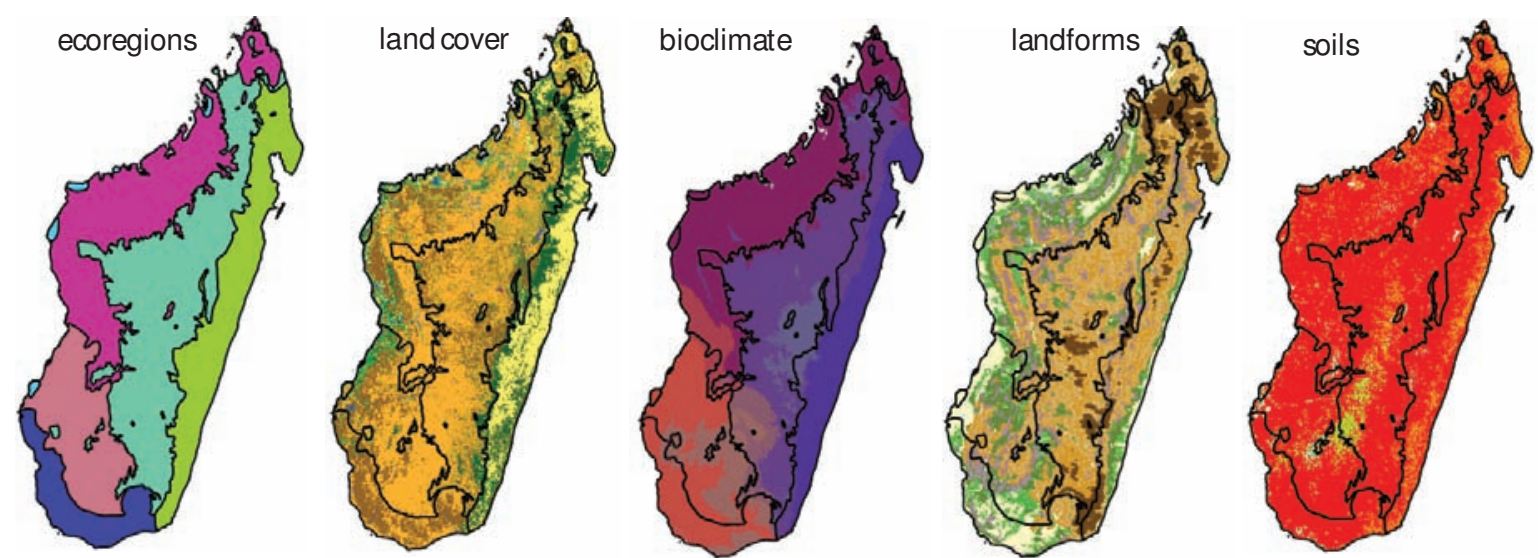

M. humid fores

M. subhumid forest

M. dry decidous forest

M. sicculent woodlands

M. spiny thickets

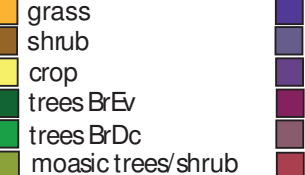

hot, v.wet

warm, wet

hot, wet

v.hot. wet

hot, moist $\square$ hot, semi-dry

v.hot, moist $\square$ v.hot, semi-dry

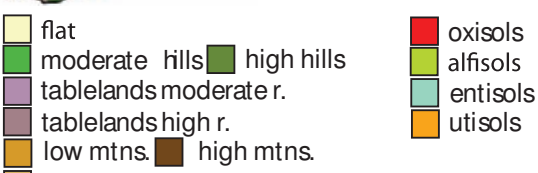

moasic trees/shrub
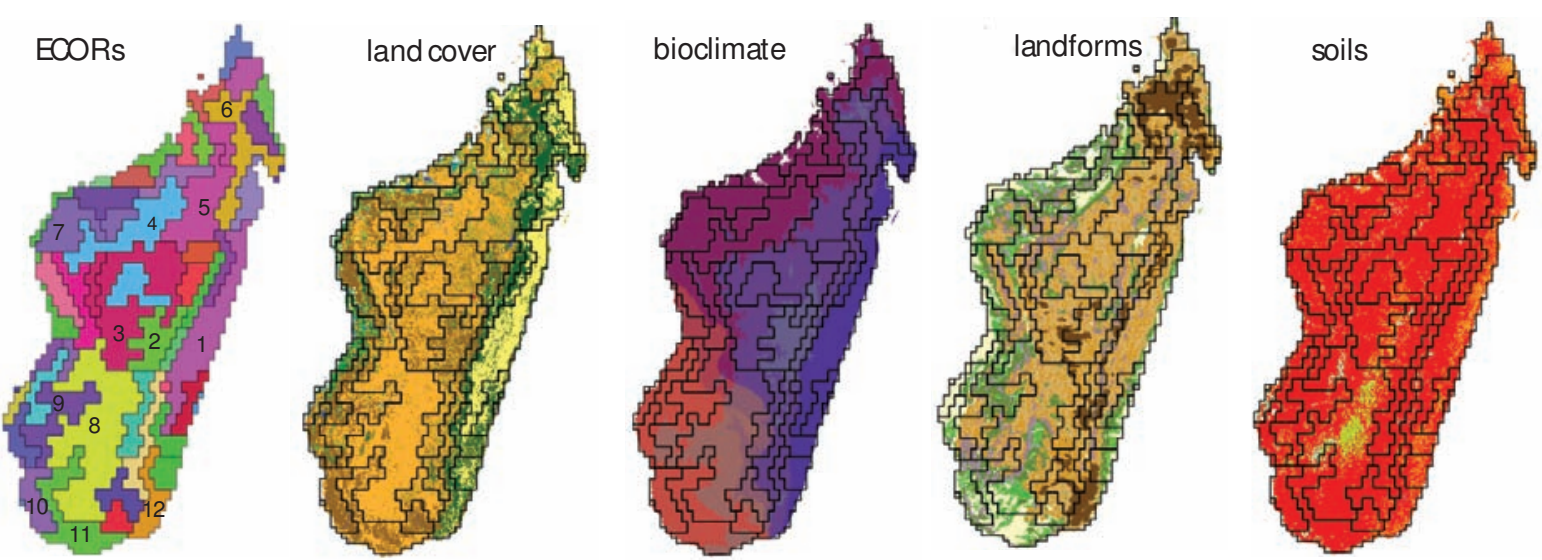

crop/tree BrEvloxisollscat. bw mtns.|hot, vwet

shrub/mosaic tree-shrub|oxisol|scat. low. mtns./low mtns/warm, wet grassmosaic tree-shrub|oxisol|scat. low. mtns./low mtns|hot, wet

grassbxisollscat. low. mtns./high hills|v. hot, wet

grassmosaic tree-shrub|oxisol|scat. low. mtns./low mtns|hot, wet/hot

tree $\mathrm{BrEv} / \mathrm{crop} \mid$ oxisol|high mtns/scat. low mtns/hot, wet/hot, v. wet

grass/shrub|oxisol|high hills/mod. hills|v. hot, wet

grass/oxisol|low mtns/scat. low mtns|hot, semi-dry/v.hot. semi-dry grass/shrub|oxisol|high hills/scat. low mtns|v. hot, semi-dry/hor, semi-dry

grass/oxisol|scat. low. mtns./high hills|v. hot, wet

shrub/grass|oxisol|high hills/flat|v. hot, semi-dry

tree BEv/crop|oxisol/utosil|high mtns/scat. low mtns/hot, wet/hot, v. wet

Figure 2: Comparison of ecoregionalizations in TEW and ECOR 30km using the island of Madagascar as an example. The upper row of maps shows TEW regions and how they divide the island's physiography. The lower row of maps shows the same for ECOR. Abbreviations: M. - Madagascar, v. - very, r. - relief, scat. scattered, BrEv - broadleave evergreen, mtns. - mountains. 

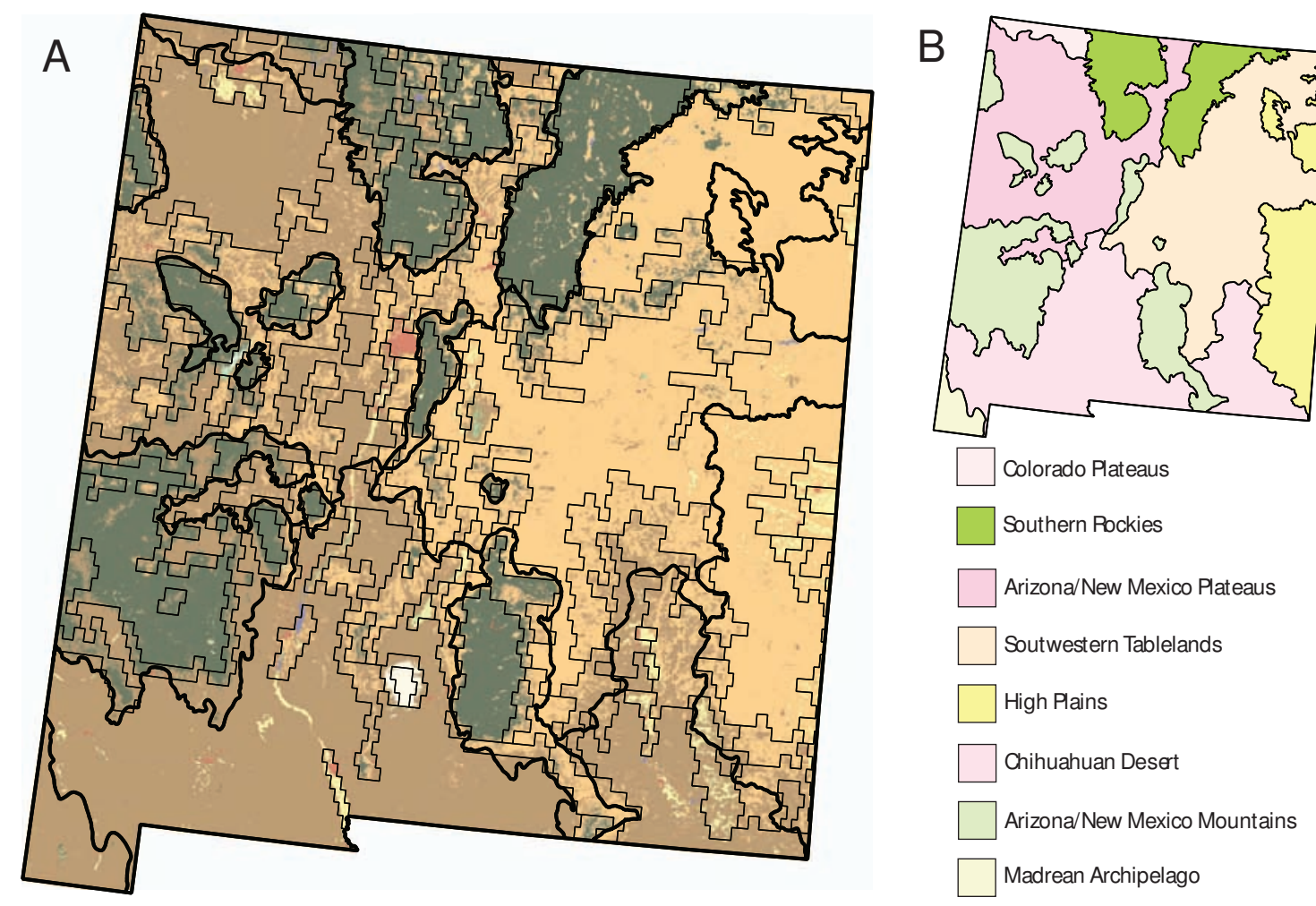

Figure 3: Comparison of ECOR 9km and EPA Level III ecoregionalizations of the state of New Mexico, U.S. (A) EPA ecoregions (thick lines) and ECOR regions (thin lines) overlying the map of land cover. (B) Eight EPA Level III ecoregions in New Mexico.

mtns./scat. low mtns.; cool, semi-dry/cold, moist. The two re-573 gions, Southwestern Tablelands and High Plains are dominated ${ }_{574}$ by the same ECOR region (grass; mollisols/aridisols; moderate 575 hills/flat; warm, semi-dry/cool, semi-dry). They differ by pre-576 dominant landforms which the present version of segmentation ${ }_{577}$ was not able to take into account.

In addition, ECOR also delineated smaller regions, where $_{579}$ pattern of land cover departs from surroundings. For example, ${ }_{58}$ in the Chihuahuan Desert ecoregion, there are several inclu- ${ }_{581}$ sions, one is the large field of white sand dunes, and another the ${ }_{582}$ San Andreas mountains just west of the dunes. ECOR delin- ${ }_{583}$ eated these features as independent regions, whereas they ap- ${ }_{584}$ pear only at the higher, IV Level of the EPA mapping.

\section{Conclusions}

A possibility of delineating ecoregions using quantitative ${ }_{589}$ methodology was discussed (McMahon et al., 2001; Loveland ${ }_{590}$ and Merchant, 2004) and attempted by Hargrove and Hoffman (2005) using multivariate clustering. However, the quantitative method presented in this paper is the first to achieve some level ${ }_{593}$ of success. This is because, instead of relying on clustering, it ${ }_{594}$ employs a method that attempts to emulate in computer code ${ }_{595}$ the qualitative, weight-of-evidence approach. The presented $d_{506}$ global delineation of ecophysiographic regions (ECOR) is the first iteration of this new method. Although, we presented a de- ${ }_{598}$ lineation based on a specific land cover dataset (CCI-LC), using different dataset of comparable resolution would yield a very599 similar result due to the fact that all land cover datasets must reflect the same on-the-ground reality. Indeed, we repeated calculations using the $1 \mathrm{~km}$ resolution GLC 2000 dataset and obtained very similar regionalization.

In addition to describing the method behind ECOR, we make available the complete, worldwide database of ECOR regions so that the scientific community can evaluate its usefulness for various tasks. We have already identified several areas where ECOR can be useful. At the minimum, it offers a valuable "first draft map" for analysts to manually modify it using their expert knowledge. This would save a lot of time and effort, and expedite updating existing maps, such as TEW. It would, perhaps, make possible a construction of the EPA-style map of ecoregions on the global scale. ECOR makes available detailed quantitative information about physiographic patterns in each region. Moreover, this information is SQL-searchable. As such data was not previously available, we need to start thinking how it could be utilized.

ECOR will get an update when the pattern-based segmentation technology achieves a multi-layer capability. The challenge of segmenting on the basis of multiple patterns simultaneously is how to incorporate similarities between patterns of individual variables into a similarity of the common, physiographic patterns. We expect that such update will result in improvement of regions' physiographic homogeneity, but at the cost of an even larger number of regions.

Acknowledgments. This work was supported by the Univer- 

nents. Environmental Conservation 14 (4), 307-309. continents. 72-82. Biosystems 148(6), 1255-1345. Remote Sensing of Environment, 113, 113, 668-679. introduction using MicroCase. Wadsworth Pub Co. Princeton University Press. sion 2.0. Tech. rep. Biogeography 14, 223-239. URL http: //grass .osgeo.org ence. Springer, Netherlands, pp. 215-227. Management 34 (1 SUPPL.), 1-21. Geosciences 80, 62-73. 10.17605/OSF.IO/SMVA7) view of biology 81(3), 237-258. tion data. Transactions in GIS 21(5), 1040-1060.
Bailey, R. G., 1989. Explanatory supplement to Ecoregions Map of the Conti- ${ }_{674}$

Bailey, R. G., 2014. Ecoregions: The ecosystem geography of the oceans and ${ }_{676}^{675}$

Bisquert, M., Bégué, A., Deshayes, M., 2015. Object-based delineation of ho- ${ }_{678}^{677}$ mogeneous landscape units at regional scale based on MODIS time series. 679 International Journal of Applied Earth Observation and Geoinformation 37, 680

Blasi, C., Capotorti, G., Copiz, R., Guida, D., Mollo, B., Smiraglia, D., Zavat- ${ }_{682}^{68}$ tero, L., 2014. Classification and mapping of the ecoregions of Italy. Plant ${ }_{683}$

Coops, N. C., Wulder, M. A., Iwanicka, D., 2009. Exploring the relative im- ${ }_{685}^{684}$ portance of satellite-derived descriptors of production, topography and land cover for predicting breeding bird species richness over Ontario, Canada. ${ }_{687}$

Corbett, M., LeRoy, M. K., 2003. Research methods in political science: $a_{689}^{688}$

Cramér, H., 2016. Mathematical Methods of Statistics (PMS-9) (Vol. 9) ${ }_{691}^{690}$

EA, 2000. Environment Australia, Revision of the Interim Biogeographic Regionalisation for Australia (IBRA) and Development of Version 5.1. Tech. ${ }_{694}$ rep., Summary Report, Canberra, Environment Australia.

ESA, 2017. European Space Agency Land Cover CCI Product User Guide Ver- ${ }_{696}{ }_{69}$

Eyre, M., Rushton, S., Luff, M., Telfer, M., 2004. Predicting the distribution ${ }_{698}$ of ground beetle species (Coleoptera, Carabidea) in Britain using land cover ${ }_{699}$ variables. Journal of Environmental Management 72, 163-174.

Fuller, R. M., Devereux, B. J., Gillings, S., Amable, G. S., Hill, R. A., 2005. ${ }_{701}^{700}$ Indices of bird-habitat preference from field surveys of birds and remote sensing of land cover: a study of south-eastern England with wider impli- ${ }_{703}$ cations for conservation and biodiversity assessment. Global Ecology and ${ }_{704}$

Gonzales, O. J., 1966. Formulating an ecosystem approach to environmental ${ }_{705}^{705}$ protection. Environmental Management 20(5), 597-605.

GRASS Development Team, 2016. Geographic Resources Analysis Support ${ }_{708}^{707}$ System (GRASS) Software. Open Source Geospatial Foundation, USA. $\quad 709$

Haber, W., 2011. An ecosystem view into the twenty-first century. In: Schwarz ${ }^{71}$ A., Jax, K. (Eds.), Ecology revisitedreflecting on concepts advancing sci- $_{712}$

Hargrove, W. W., Hoffman, F. M., 2005. Potential of multivariate quantita- ${ }_{714}^{713}$ tive methods for delineation and visualization of ecoregions. Environmental ${ }_{715}$

Heikkinen, R. K., Luoto, M., Virkkala, R., Rainio, K., 2004. Effects of habitat ${ }_{717}^{716}$ cover, landscape structure and spatial variables on the abundance of birds in ${ }_{718}$ an agricultural-forest mosaic. Journal of Applied Ecology 41, 824-835.

Hengl, T., deJesus, J. M., Heuvelink, G. B., Gonzalez, M. R., Kilibarda, ${ }_{720}^{719}$ M., Blagotic, A., Shangguan, W., Wright, M. N., Geng, X., Bauer- ${ }^{721}$ Marschallinger, B., Guevara, M. A., 2017. SoilGrids250m: Global gridded soil information based on machine learning. PloS One 12(2), e0169748.

Jasiewicz, J., Netzel, P., Stepinski, T., 2015. GeoPAT: A toolbox for patternbased information retrieval from large geospatial databases. Computers and ${ }_{725}$

Jasiewicz, J., Stepinski, T. F., Niesterowicz, J., 2017. Multi-scale seg- ${ }^{72}$ mentation algorithm for pattern-based partitioning of large categorical ${ }_{728}$ rasters. Computers \& Geosciences submitted, preprint at EarthArXiv (DOI: ${ }_{729}$

Jax, K., 2006. Ecological units: definitions and application. The quarterly re-

Karagulle, D., Frye, C., Sayre, R., Breyer, S., Aniello, P., Vaughan, R., Wright, D., 2017. Modeling global hammond landform regions from 250-m eleva-

Kerr, J. T., Southwood, T. E., Cihlar, J., 2001. Remotely sensed habitat diversity predicts butterfly species richness and community similarity in Canada. Proceedings of the National Academy of Sciences 98(20), 11365-11370.
Klijn, F., deWaal, R. W., Voshaar, J. H., 1995. Ecoregions and ecodistricts: Ecological regionalizations for the Netherlands' environmental policy. Environmental Management 19(6), 797-813.

Kumar, J., Mills, R. T., Hoffman, F. M., Hargrove, W. W., 2011. Parallel kmeans clustering for quantitative ecoregion delineation using large data sets. Procedia Computer Science 4, 1602-1611.

Larsen, D. P., Thorton, K. W., Urquart, N. S., Paulsen, S. G., 1994. The role of sample surveys for monitoring the conditions of the Nations lakes. Environmental Monitoring and Assessment 32: 32, 101-134.

Lin, J., 1991. Divergence Measures Based on the Shannon Entropy. IEEE Transactions on Information Theory 37 (1), 145-151.

Loveland, T. R., Merchant, J. M., 2004. Ecoregions and ecoregionalization: geographical and ecological perspectives. Environmental management 34(1), S1-S13.

Luoto, M., Heikkinen, R. K., Pöyry, J., Saarinen, K., 2006. Determinants of biogeographical distribution of butterflies in boreal regions. Journal of Biogeography 33, 1764-1778.

Luoto, M., Virkkala, R., Heikkinen, R., 2007. The role of land cover in bioclimatic models depends on spatial resolution. Global Ecology and Biogeography $16,16,34-42$.

Maes, D., Gilbert, M., Titeux, N., Goffart, P., Dennis, R. L. H., 2003. Prediction of butterfly diversity hotspots in Belgium: a comparison of statistically focused and land use-focused models. Journal of Biogeography 30, 19071920.

McMahon, G., Gregonis, S. M., Waltman, S. W., Omernik, J. M., Thorson, T. D., Freeouf, J. A., Rorick, A. H., Keys, J. E., apr 2001. Developing a Spatial Framework of Common Ecological Regions for the Conterminous United States. Environmental Management 28 (3), 293-316.

Metzger, M. J., Bunce, R. G. H., Jongman, R. H. G., Sayre, R., Trabucco, A., Zomer, R., 2013. A high-resolution bioclimate map of the world: A unifying framework for global biodiversity research and monitoring. Global Ecology and Biogeography 22 (5), 630-638.

Niesterowicz, J., Stepinski, T. F., 2017. Pattern-based, multi-scale segmentation and regionalization of EOSD land cover. Int. J. Appl. Earth Obs. Geoinformation 62, 192-200.

Niesterowicz, J., Stepinski, T. F., Jasiewicz, J., 2016. Unsupervised regionalization of the conterminous U.S. into hierarchical landscape pattern types. International Journal of Geographical Information Science 30(7), 1450-1468.

Olson, D. M., Dinerstein, E., Wikramanayake, E. D., Burgess, N. D., Powell, G. V. N., Underwood, E. C., D'amico, J. a., Itoua, I., Strand, H. E., Morrison, J. C., Loucks, C. J., Allnutt, T. F., Ricketts, T. H., Kura, Y., Lamoreux, J. F., Wettengel, W. W., Hedao, P., Kassem, K. R., 2001. Terrestrial Ecoregions of the World: A New Map of Life on Earth. BioScience 51 (11), 933.

Omernik, J. M., 1987. Ecoregions of the Conterminous United States. Annals of the Association of American Geographers 77 (1), 118-125.

Omernik, J. M., Griffith, G. E., 2014. Ecoregions of the Conterminous United States: Evolution of a Hierarchical Spatial Framework. Environmental Management 54 (6), 1249-1266.

Painho, M., Farral, H., Barata, F., 1996. Digital map of European ecological regions (DMEER). Its concept and elaboration. In: Second Joint European Conference and Exhibition on Geographical Information (Vol. 1). IOS Press, pp. 437-446.

Pearson, R. G., Dawson, T. P., Liu, C., 2004. Modelling species distributions in Britain: a hierarchical integration of climate and land-cover data . Ecography 27, 285-298.

Sayre, R., Dangermond, J., Frye, C., Vaughan, R., Aniello, P., Breyer, S., Cribbs, D., Hopkins, D., Nauman, R., Derrenbacher, W., Wright, D., 2014. A new map of global ecological land units - an ecophysiographic stratification approach. Tech. rep., Washington, DC: Association of American Geographers.

Siriwardena, G. M., Crick, H. Q. P., Baillie, S. R., Wilson, J. D., 2000. Agricultural land-use and the spatial distribution of granivorous lowland farmland birds. Ecography 23, 702-719. 


\title{
Supplement S1: Global Maps of Regionalization Metrics
}

\author{
Towards machine ecoregionalization of Earth's landmass using pattern segmentation \\ method
}

\section{Description}

This supplement contains figures each containing a set of maps showing spatial distributions of regions inhomogeneity, isolation, and an overall quality (1 - inhomogeneity/isolation) of regionalization with respect to a given physiographic variable. As there are four variables (land cover, soils, landforms, and bioclimate) and three regionalizations (ECOR, TEW, and BEC), there are twelve figures. Nine of these figures have three panels (inhomogeneity, isoloation, and quality), the remaining three figures, corresponding to the bioclimatic variable, have only two panels. This is because, unlike in the case of the remaining three variables, we measure inhomogeneity of regions with respect to bioclimate in terms of entropy so inhomogeneity and isolation do not have the same units, and the quality metric is not defined.

The values of inhomogeneity, isolation, and quality vary from 0 to 1 , except for the biodiversity variable where the value of inhomogeneity varies from 0 to $\log _{2} 37$. For inhomogeneity the smaller values are more desirable, but for isolation and quality, the larger values are more desirable. Legends in the figures are arranged so the gradation from a green color to a red color indicates a decrease in desirability.

For ECOR and TEW metrics are calculated using $9 \mathrm{~km} \times 9 \mathrm{~km}$ sites, and for BEC using $30 \mathrm{~km} \times 30 \mathrm{~km}$ sites (see section 2.2 of the paper for the explanation). 

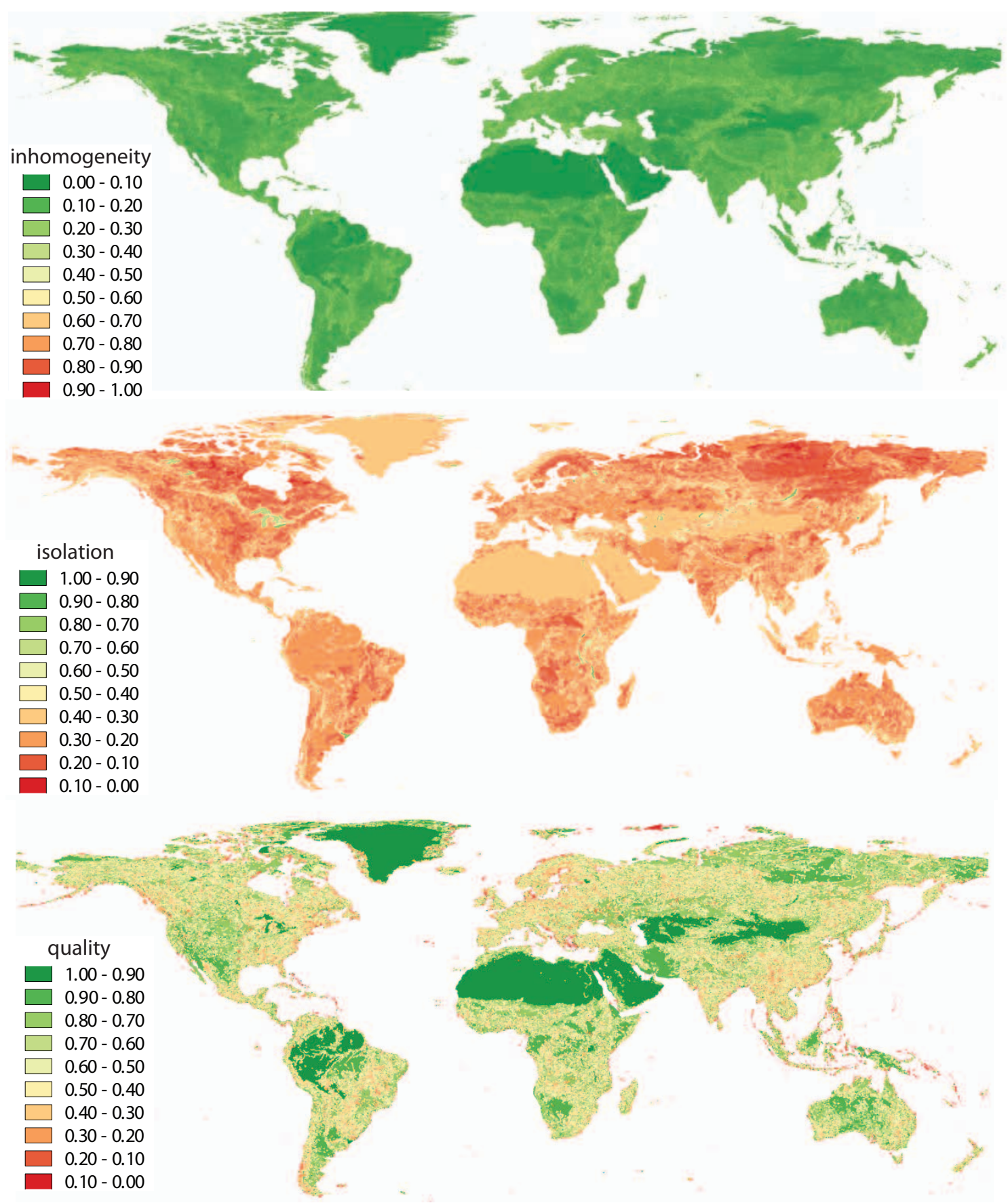

Figure 1: Maps of quality metrics, inhomogeneity (top), isolation (middle), and quality (bottom) with respect to land cover for the ECOR regionalization. 

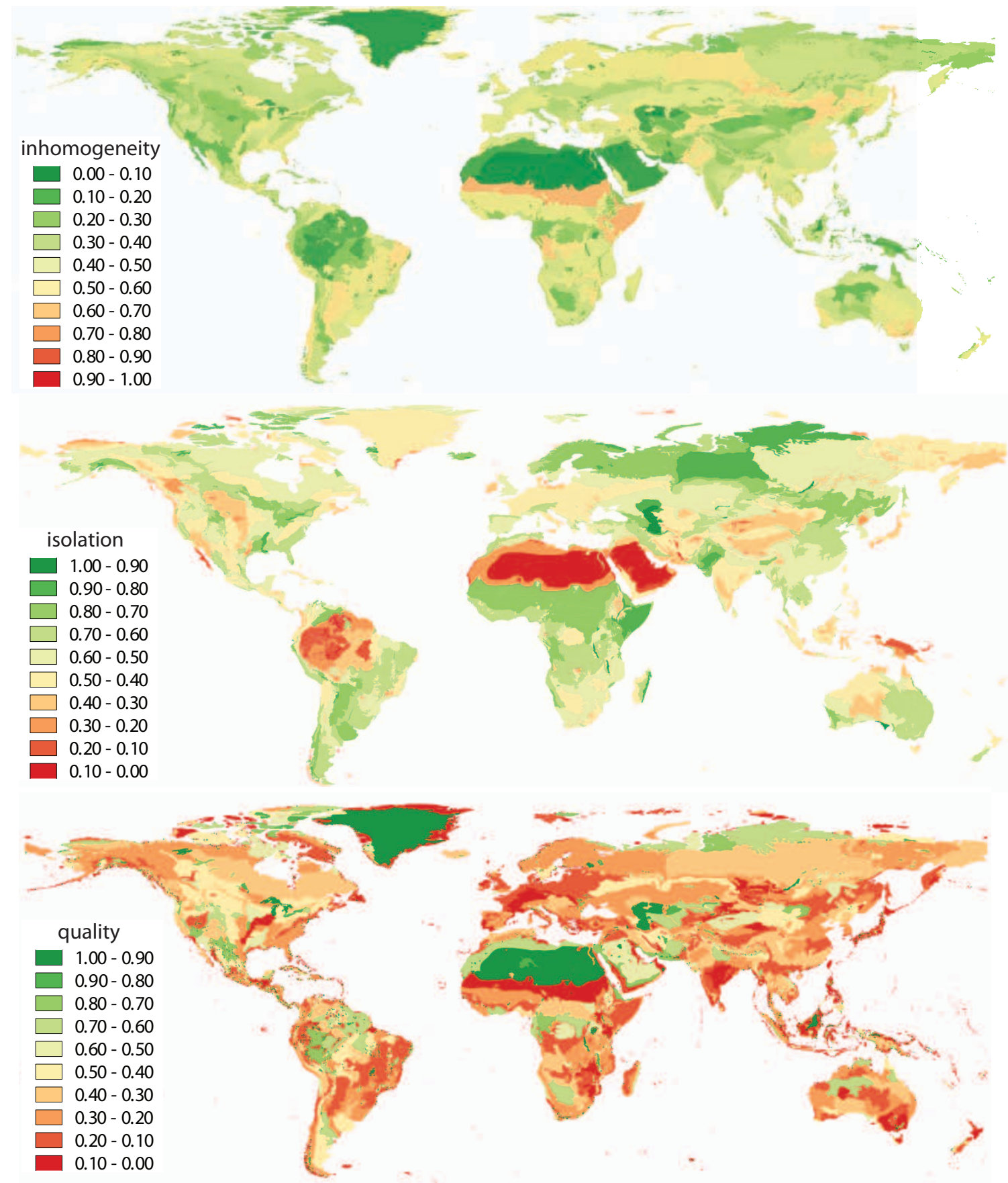

Figure 2: Maps of quality metrics, inhomogeneity (top), isolation (middle), and quality (bottom) with respect to land cover for the TEW regionalization. 

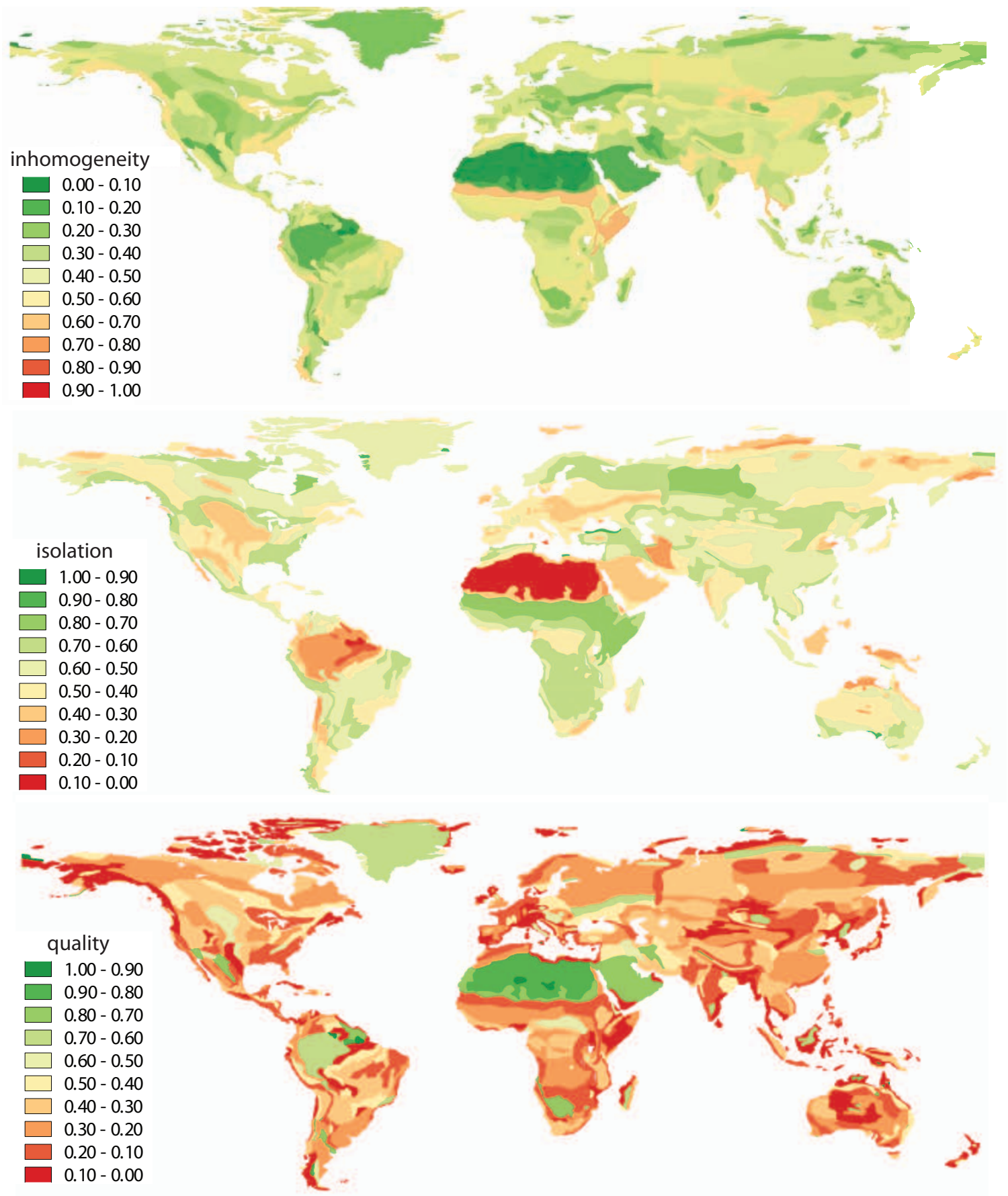

Figure 3: Maps of quality metrics, inhomogeneity (top), isolation (middle), and quality (bottom) with respect to land cover for the $\mathbf{B E C}$ regionalization. 

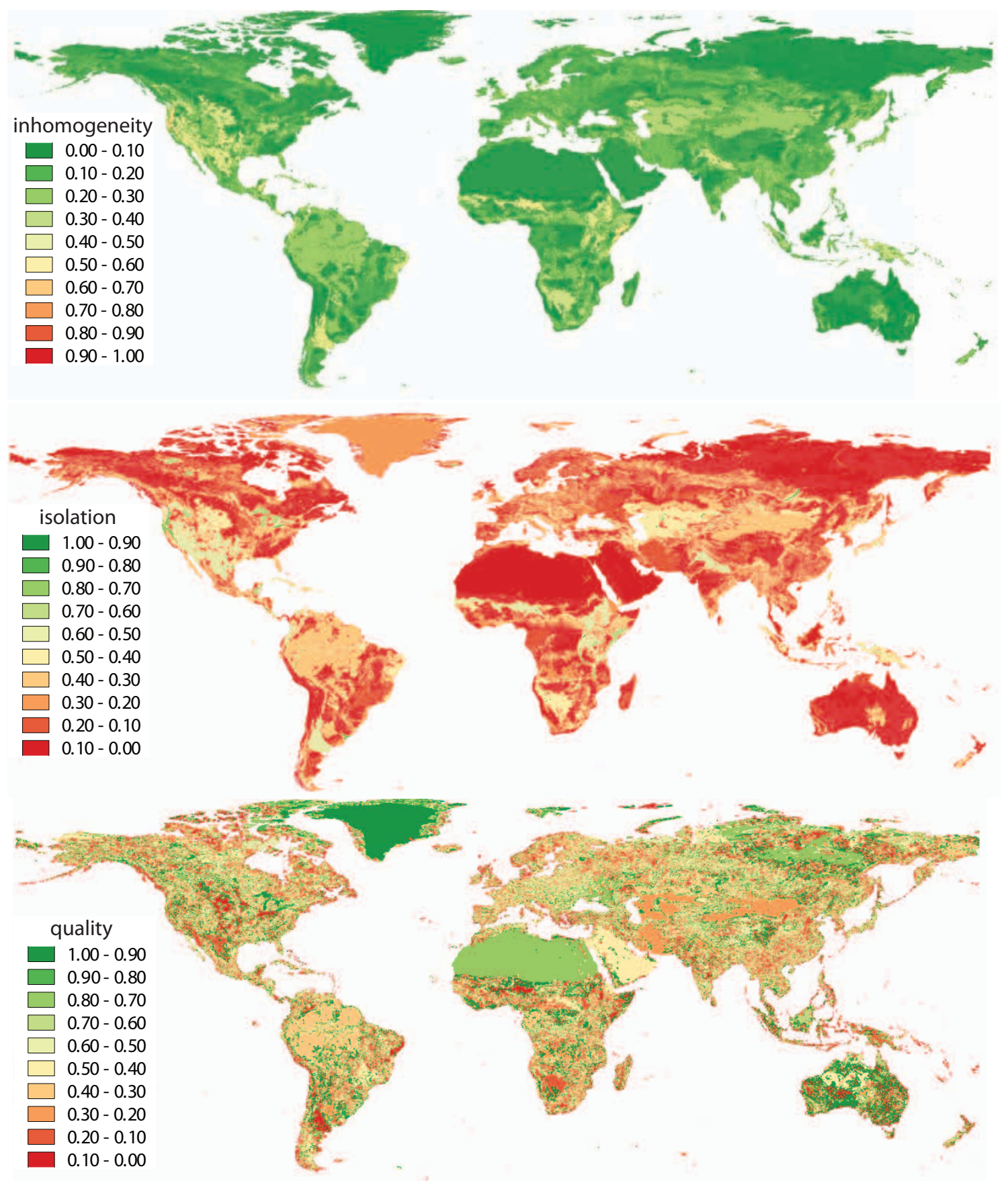

Figure 4: Maps of quality metrics, inhomogeneity (top), isolation (middle), and quality (bottom) with respect to soils for the ECOR regionalization. 

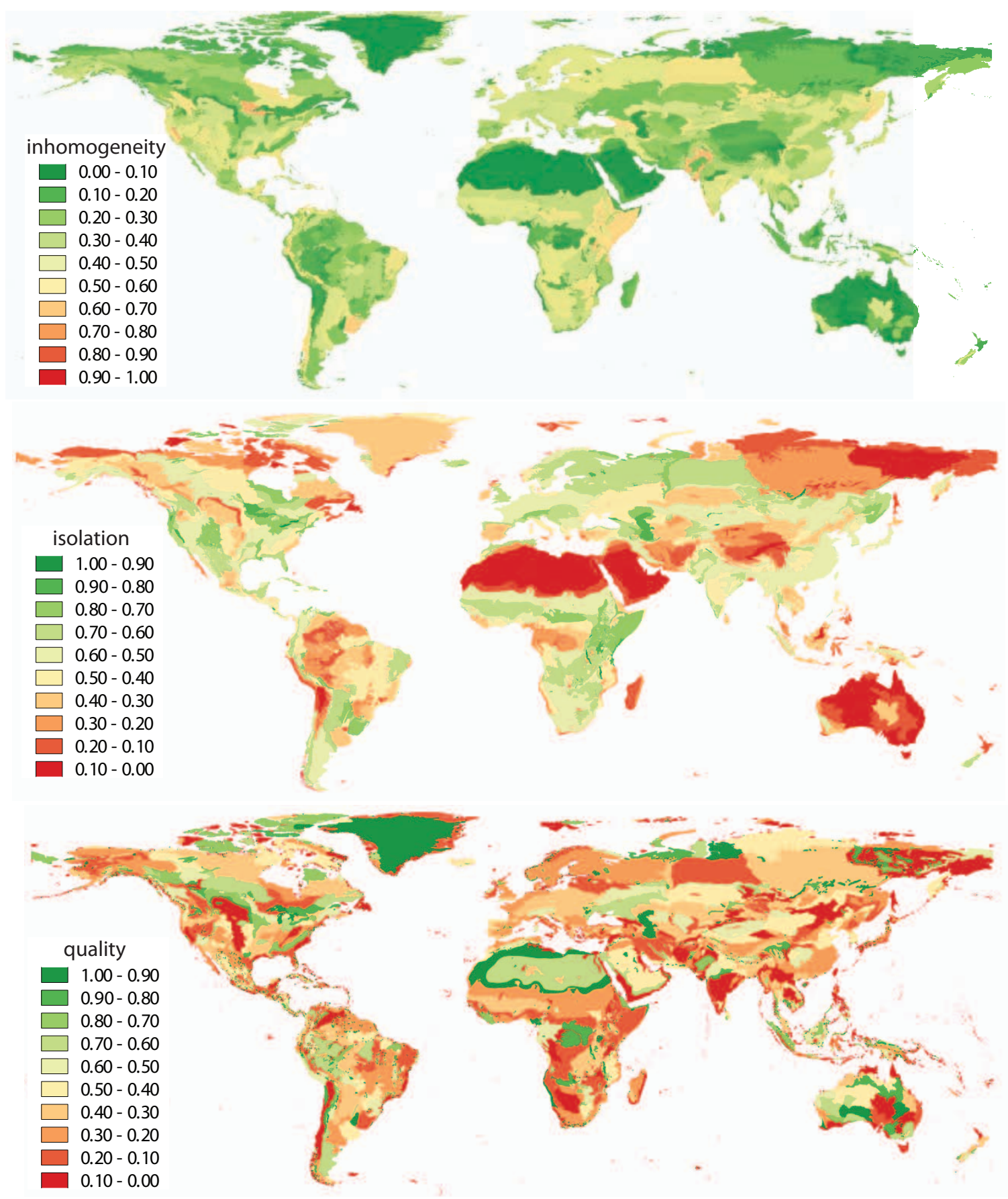

Figure 5: Maps of quality metrics, inhomogeneity (top), isolation (middle), and quality (bottom) with respect to soils for the $\mathbf{T E W}$ regionalization. 

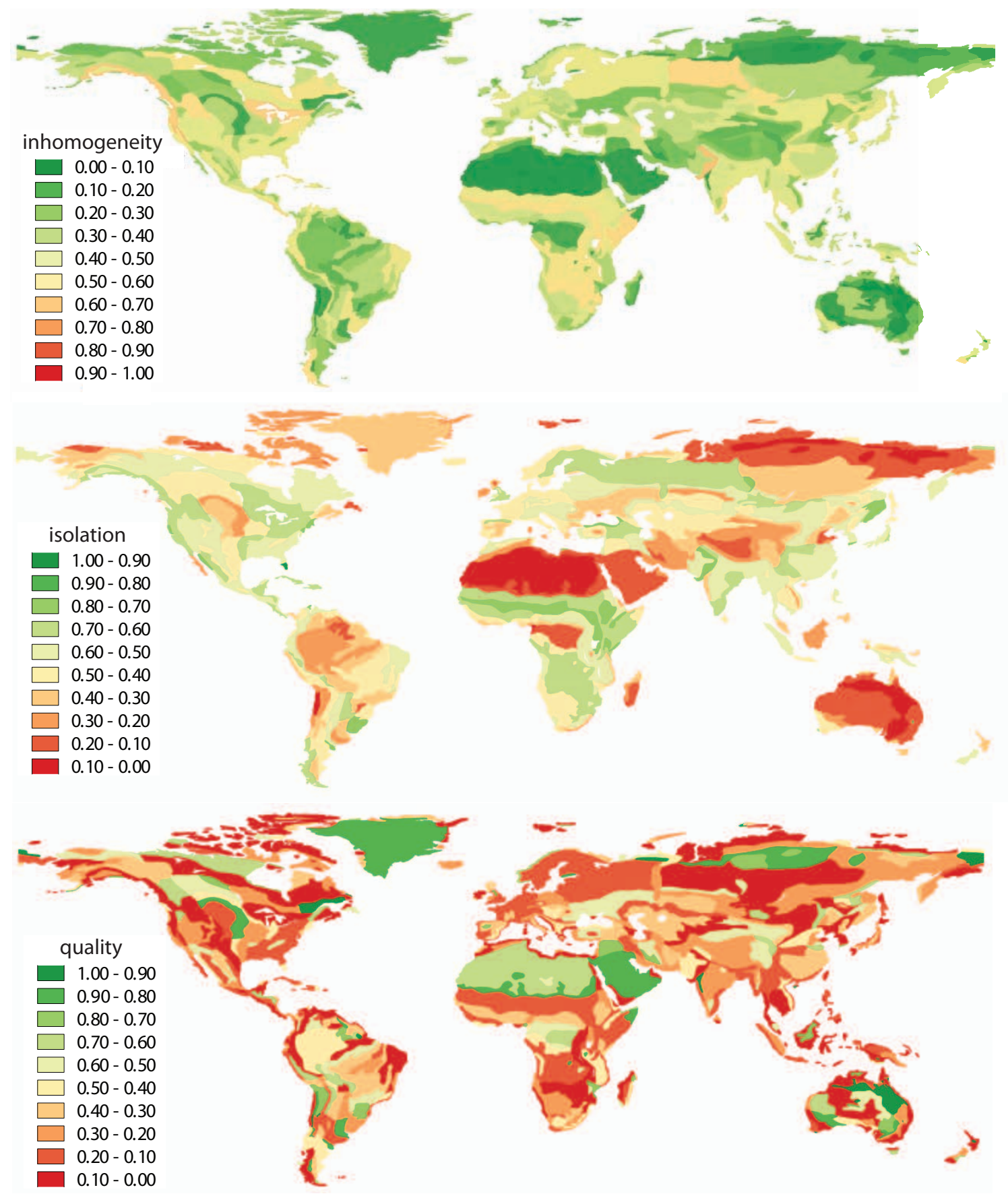

Figure 6: Maps of quality metrics, inhomogeneity (top), isolation (middle), and quality (bottom) with respect to soils for the $\mathbf{B E C}$ regionalization. 

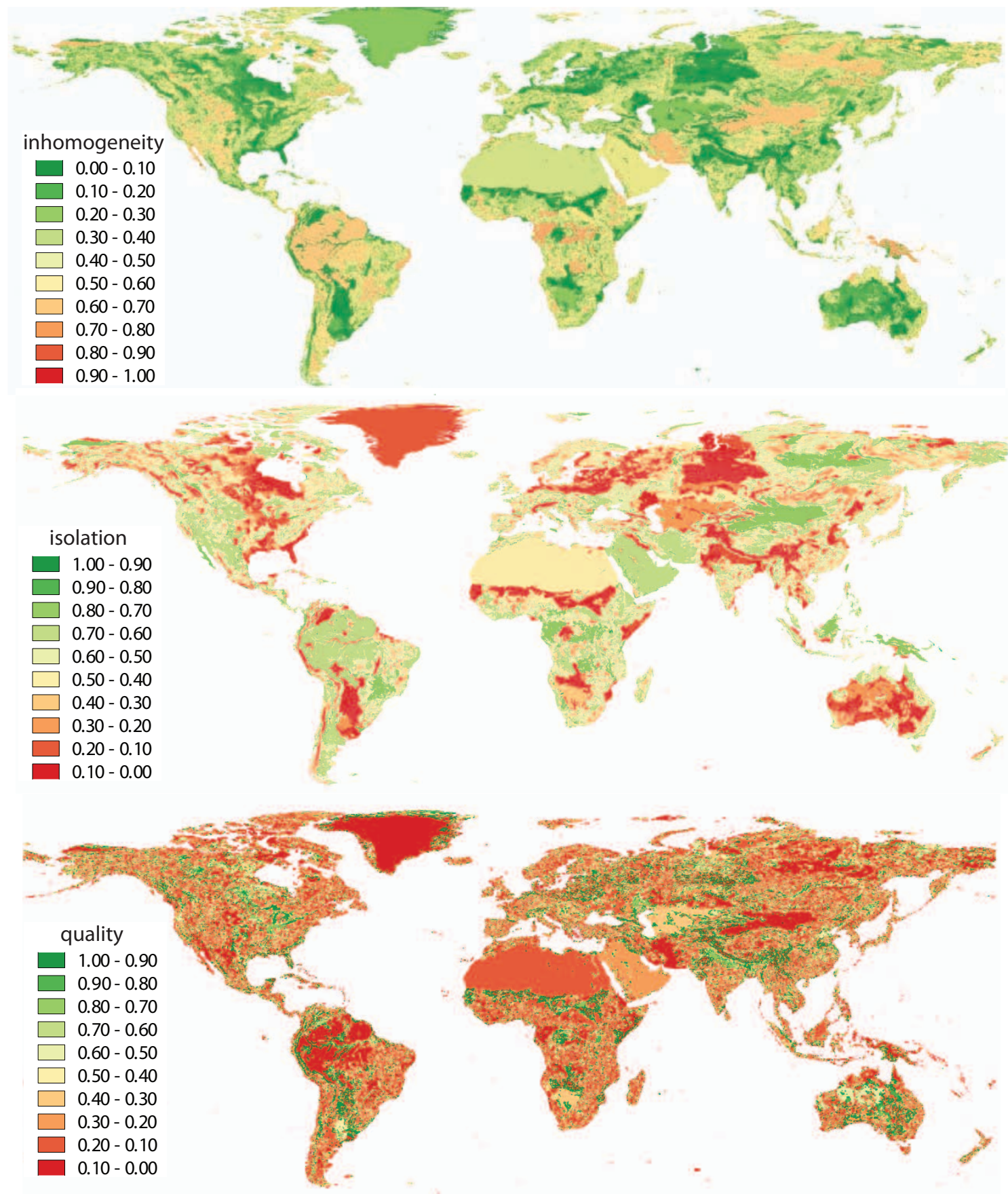

Figure 7: Maps of quality metrics, inhomogeneity (top), isolation (middle), and quality (bottom) with respect to landforms for the ECOR regionalization. 


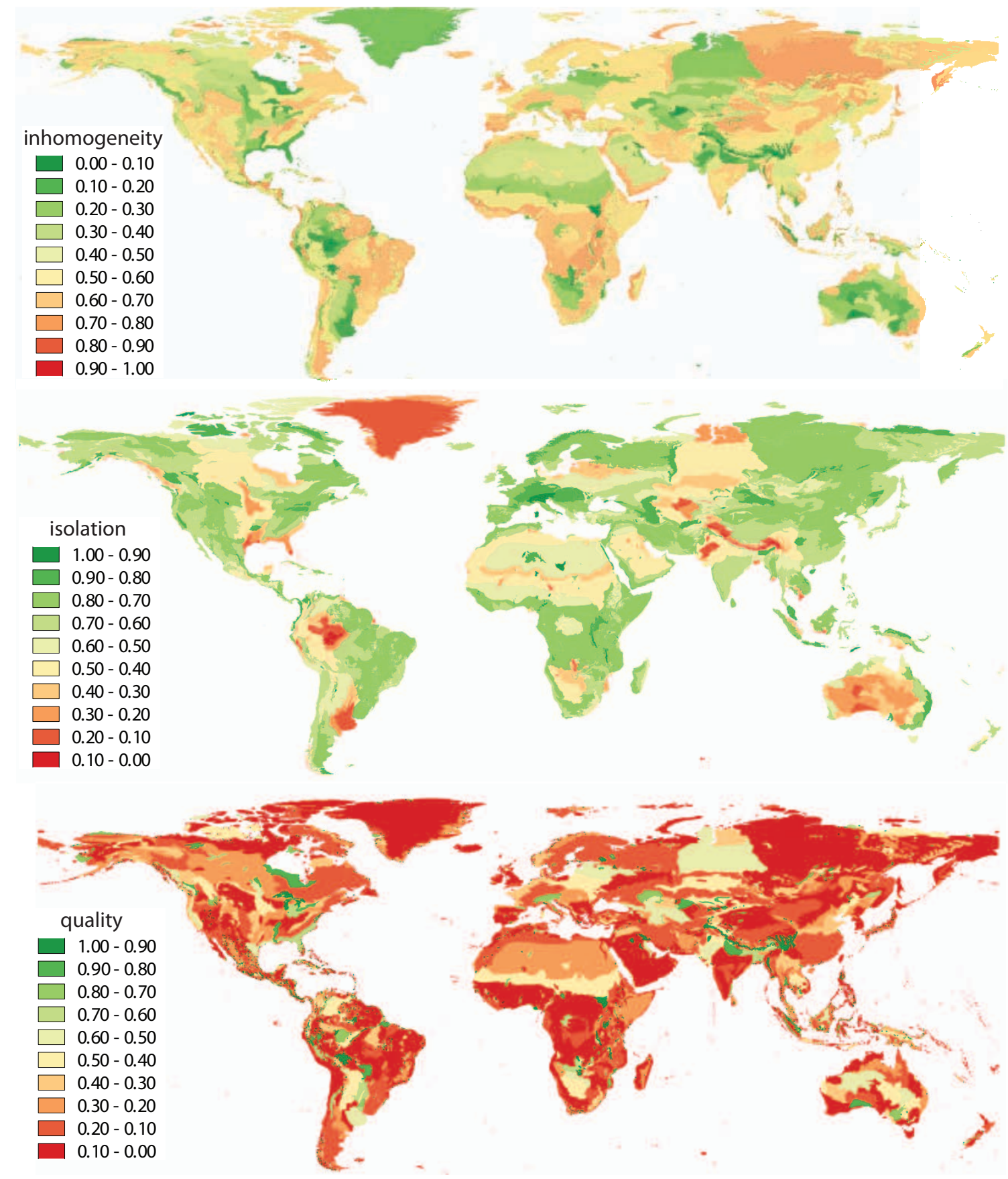

Figure 8: Maps of quality metrics, inhomogeneity (top), isolation (middle), and quality (bottom) with respect to landforms for the TEW regionalization. 

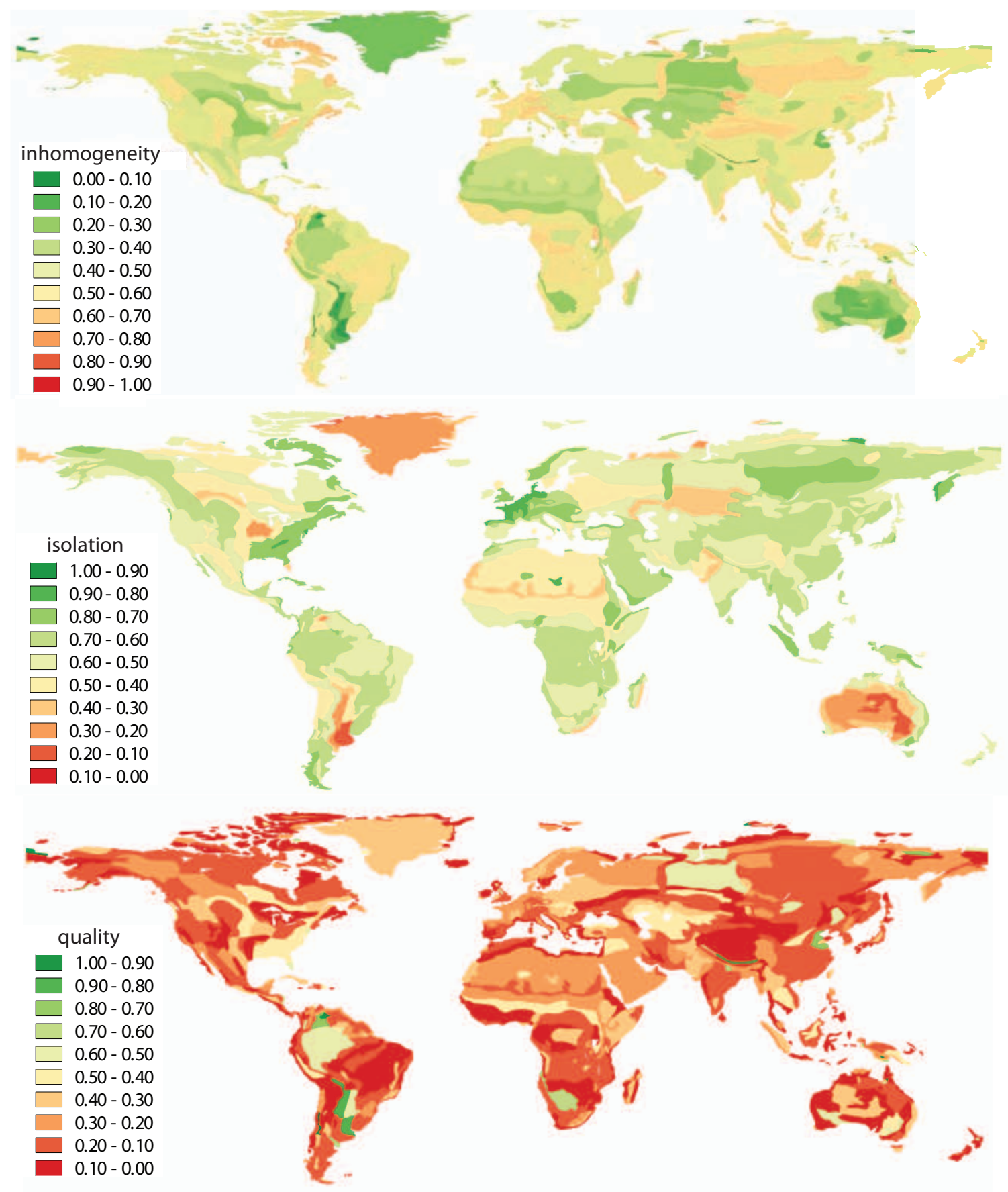

Figure 9: Maps of quality metrics, inhomogeneity (top), isolation (middle), and quality (bottom) with respect to landforms for the BEC regionalization. 


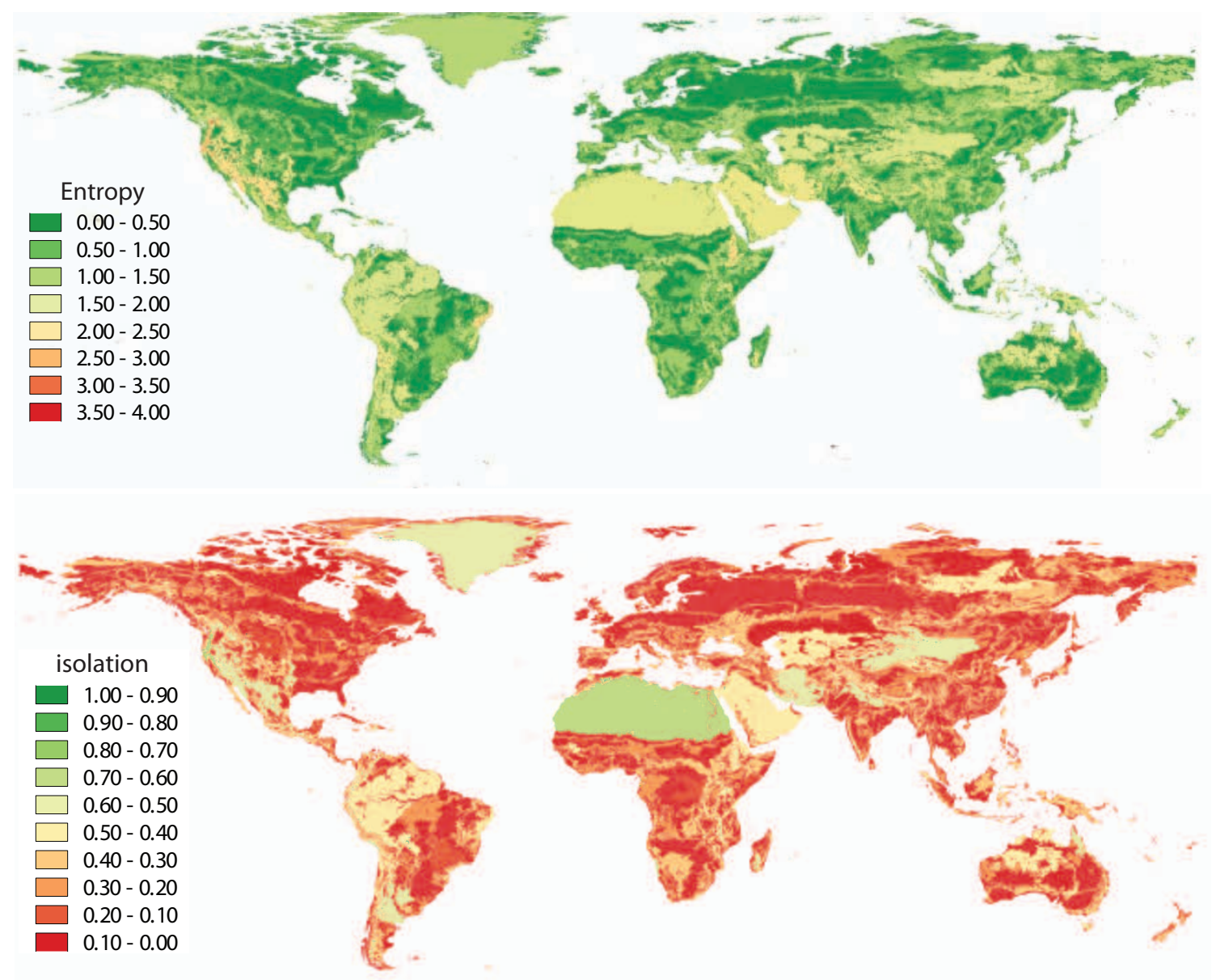

Figure 10: Maps of quality metrics, inhomogeneity (top), isolation (middle), and quality (bottom) with respect to bioclimate for the ECOR regionalization. 

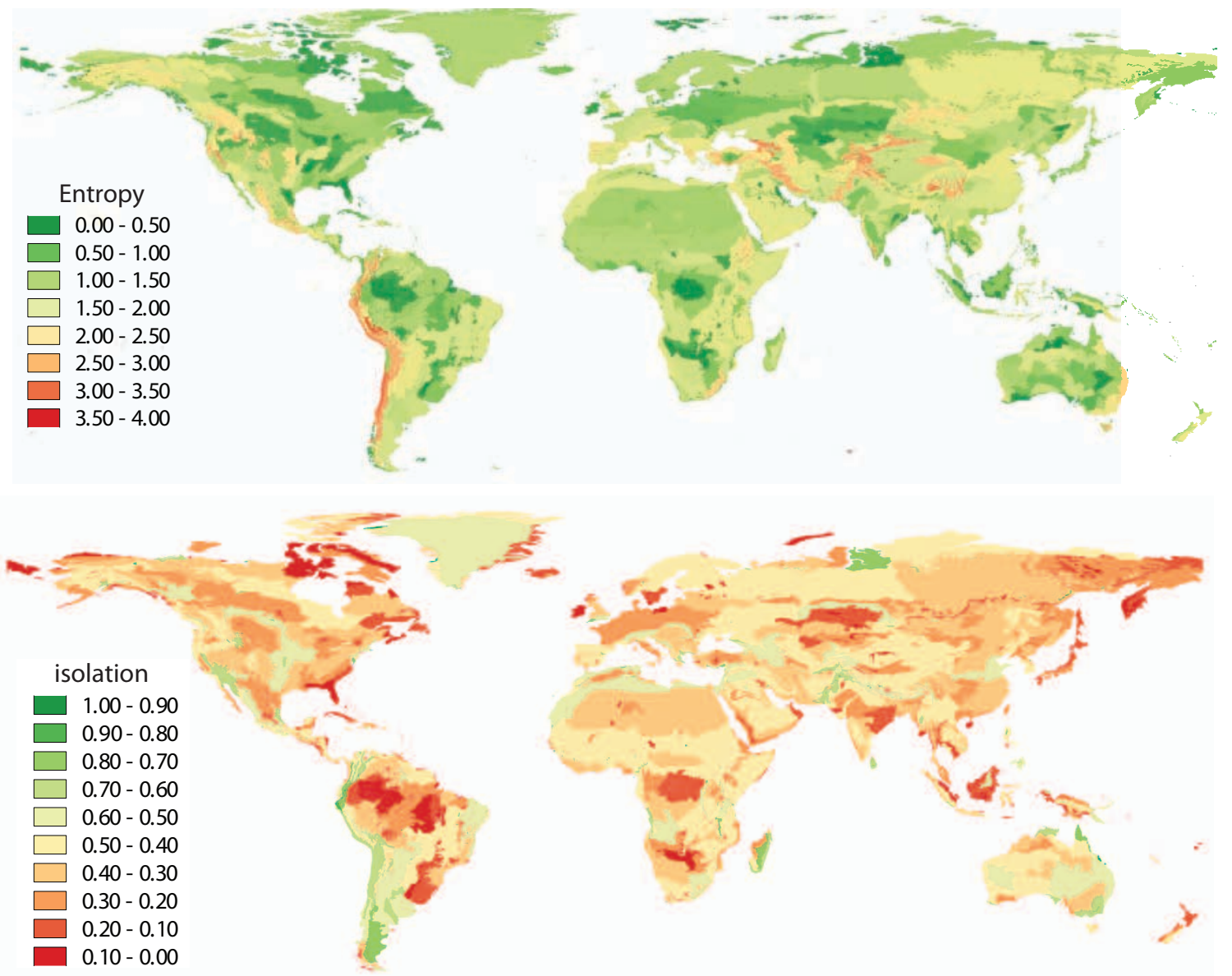

Figure 11: Maps of quality metrics, inhomogeneity (top), isolation (middle), and quality (bottom) with respect to bioclimate for the TEW regionalization. 


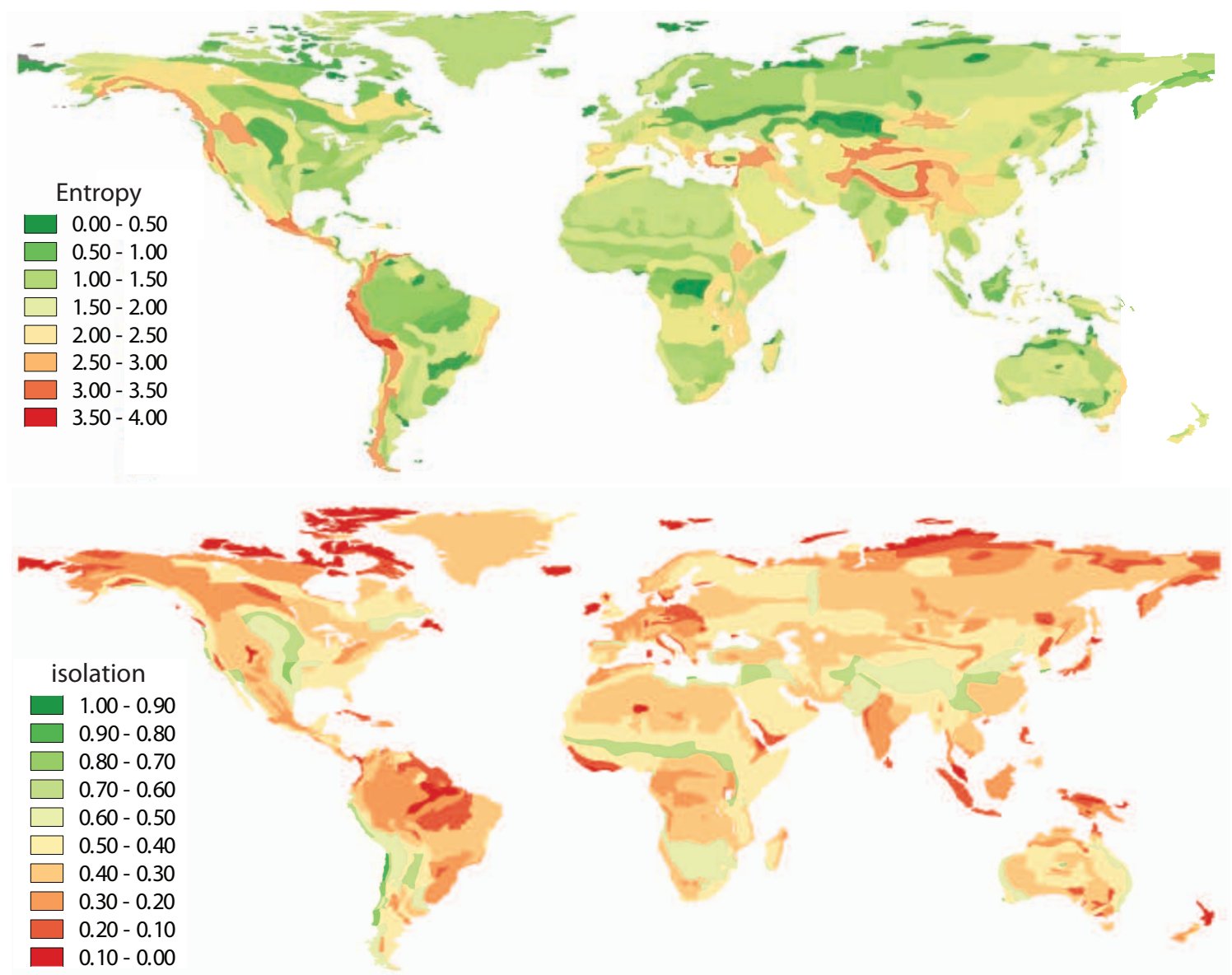

Figure 12: Maps of quality metrics, inhomogeneity (top), isolation (middle), and quality (bottom) with respect to bioclimate for the $\mathbf{B E C}$ regionalization. 


\title{
Supplement S2: Inhomogeneity and Isolation Metrics
}

\author{
Towards machine ecoregionalization of Earth's landmass using pattern segmentation \\ method
}

\section{Co-occurrence histograms}

Recall from section 2.1 that the landmass is tessellated into sites - square blocks of cells in the variable categorical raster. For the numerical description of a pattern of variable's categories in the site we use a histogram of category co-occurrence pattern features [Barnsley and Barr, 1996; Chang and Krumm, 1999]. A co-occurrence feature is a pair of categories assigned to two neighboring cells. Features are extracted from a site by combining co-occurrence matrices calculated for eight different displacement vectors along principal directions. For a raster with $k$ possible categories, the result is a symmetric matrix which we reduce to a histogram with $d=$ $\left(k^{2}+k\right) / 2$ bins. Fig. 1 show examples of co-occurrence histograms stemming from two different hypothetical sites. In this hypothetical case $k=4$ resulting in a co-occurrence histograms with 10 bins. In the case of CCI-LC, $k=22$ and the co-occurrence histogram has 253 bins. A bin in a histogram gives a (normalized; divided by the sum of all bins) number of co-occurrences (either horizontal, vertical or diagonal) between given two categories. The $k$ bins correspond to the co-occurrence of same-category pairs and their values reflect both, the abundance of the category and its spatial arrangement. The remaining $\left(k^{2}-k\right) / 2$ bins correspond to cooccurrences between different-categories pairs and their values reflect a geometric configuration of the pattern.
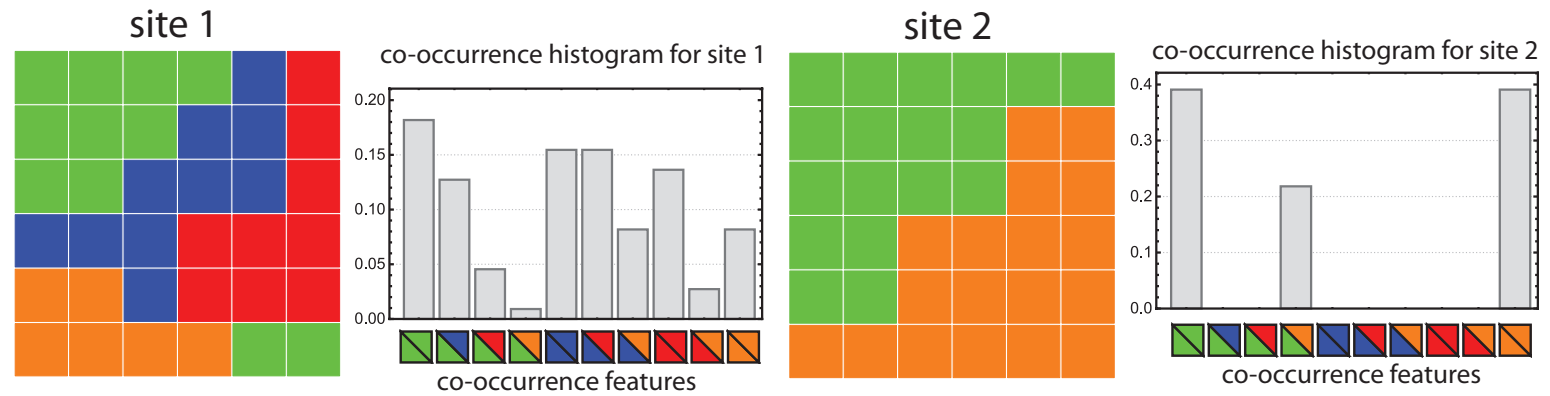

Figure 1: Co-occurrence histograms for two hypothetical sites with different patterns of variable categories. Four colors, red, blue, green, and orange indicate the four categories of the variable. 


\section{Dissimilarity measure}

We use the Jensen-Shannon Divergence (JSD) [Lin, 1991] as a measure of dissimilarity between two sites represented by corresponding normalized co-occurrence histograms $M_{1}$ and $M_{2}$. The JSD expresses the informational distance between the two histograms as a deviation between Shannon's entropy of the conjugate of the two histograms $\left(M_{1}+M_{2}\right) / 2$ and the mean entropy of individual histograms $M_{1}$ and $M_{2}$. The value of JSD, denoted by $d\left(M_{1}, M_{2}\right)$, is given by the following formula:

$$
d\left(M_{1}, M_{2}\right)=H\left(\frac{M_{1}+M_{2}}{2}\right)-\frac{1}{2}\left[H\left(M_{1}\right)+H\left(M_{2}\right)\right]
$$

where $H(M)$ indicates a value of the Shannon's entropy of the histogram $M$ :

$$
H(M)=-\sum_{i=1}^{|M|} m_{i} \log _{2} m_{i} .
$$

where $m_{i}$ is the value of $i t h$ bin in the histogram $M$ and $|M|$ is the number of bins (the same for both histograms). For normalized histograms, the JSD dissimilarity always takes values from 0 to 1 with the value of 0 indicating that two motifels are identical, and the value of 1 indicating maximum dissimilarity (none of the classes existing in one motifel can be found in the other).

\section{Linkage, inhomogeneity, and isolation}

The segmentation algorithm not only requires calculating a value of dissimilarity between two sites (eq. 1) but also a value of dissimilarity between two segments (sets of sites), which we refer to as a linkage. Consider two segments, $S_{1}=\left\{M_{1,1}, \ldots, M_{1, k 1}\right\}$ consisting of $k 1$ sites and $S_{2}=\left\{M_{2,1}, \ldots, M_{2, k 2}\right\}$ consisting of $k 2$ sites. To measure a dissimilarity between these two segments we use the so-called average linkage or Unweighted Pair Group Method with Arithmetic Mean (UPGNA) [Sokal and Michener, 1958] given by

$$
D\left(S_{1}, S_{2}\right)=\frac{1}{k 1 k 2} \sum_{i=1}^{k 1} \sum_{j=1}^{k 2} d\left(M_{1, i}, M_{2, j}\right)
$$

where function $d(x, y)$ is given by eq.(1). The value of $D\left(S_{1}, S_{2}\right)$ has a range between 0 and 1 because the values of $d$ are restricted to this range.

Let $S$ be a focus segment and $S_{1}, \ldots, S_{N}$ be its neighbors. The isolation metrics $\gamma$ is a weighted average linkage between the focus segment and its $N$ neighbors,

$$
\gamma(S)=\frac{1}{N} \sum_{i=1}^{N} w_{i} D\left(S, S_{i}\right)
$$

where $w_{i}$ are the weight set to a fraction of focus segment $S$ perimeter shared with segment $S_{i}$. Isolation is a property of a single segment, its value has a range between 0 and 1 because the values of $D$ are restricted to this range. Large values of $\gamma$ indicate that a focus segment is dissimilar to its neighbors. Fig. 2 illustrates the concept of isolation. 


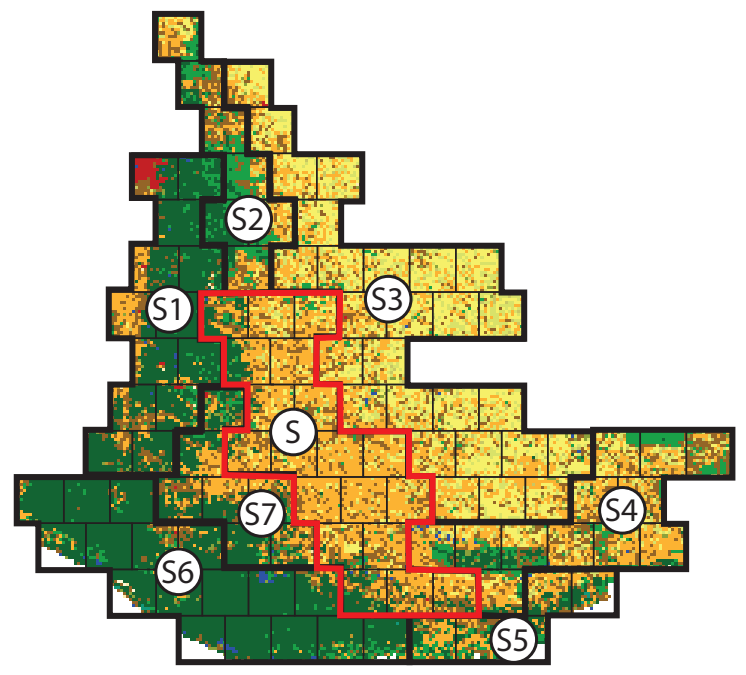

Figure 2: Focus segment $S$ (outlined in red) has seven neighbors labeled as $S_{1}$ to $S_{7}$ and outlined in black. A linkage $D$ is calculated between $S$ and every neighbor. The seven values of $D$ are averaged using weights which correspond to lengths of borders between $S$ and the neighbors. The value of isolation (with respect to land cover) for $S$ is $\gamma=0.38$ whereas its inhomogeneity is 0.11 .

Inhomogeneity is also a property of a single segment; it measures a degree of mutual dissimilarity between all sites within the segment. As a measure of inhomogeneity, we use an average distance between all distinct pairs of sites in a segment. For a segment $S=\left\{M_{1}, \ldots, M_{k 1}\right\}$ with $k 1$ sites the inhomogeneity is given as:

$$
\delta(S)=\frac{1}{k 1(k 1-1)} \sum_{i} \sum_{j \neq i} d\left(M_{i}, M_{j}\right)
$$

as there is $k 1(k 1-1)$ distinct pairs of motifels in the segment $S$. The value of $\delta$ has a range between 0 and 1 because values of $d$ are restricted to this range. The small value of $\delta$ indicates that all sites in the segment represent consistent patterns so the segment is pattern-homogeneous. Note that segment is considered homogeneous even if its constituent sites represent complex patterns of categories as long as the pattern of this complexity is approximately the same among all sites within a segment. Segment $S$ in Fig. 2 has 19 sites. To calculate $\delta(S)$ we first calculate $19 \times 18=324$ values of dissimilarity (eqn. 1) (between every pair of sites in $S$ ) and then calculate an unweighted average.

\section{References}

Barnsley, M.J. and Barr, S.L., 1996. Inferring urban land use from satellite sensor images using kernel-based spatial reclassification. Photogrammetric engineering and remote sensing, 62 (8), 949-958. 
Chang, P. and Krumm, J., 1999. Object recognition with color cooccurrence histograms. In: Proceedings of IEEE Computer Society Conference on Computer Vision and Pattern Recognition, Vol. 2 Fort Collins, CO: IEEE, 498-504.

Lin, J., 1991. Divergence measures based on the Shannon entropy. IEEE Transactions on Information Theory, 37 (1), 145-151.

Sokal, R. R., Michener, C., 1958. A statistical method for evaluating systematic relationships. Univ. Kansas Sci. Bull. 38, 1409-1438. 


\title{
Supplement S3: Legends to categories of physiographic variables
}

\author{
Towards machine ecoregionalization of Earth's landmass using pattern segmentation \\ method
}

This supplement contains legends to the four physiographic variables we use in the paper. The colors are as they appear in the rasters of these variables we make available for download from http://sil.uc.edu. The value is the number in the raster that corresponds to a given category. It is also a number utilized for auto-generation of 16-digits codes for each region; use these legends to decipher a code. The label is the name of a category.

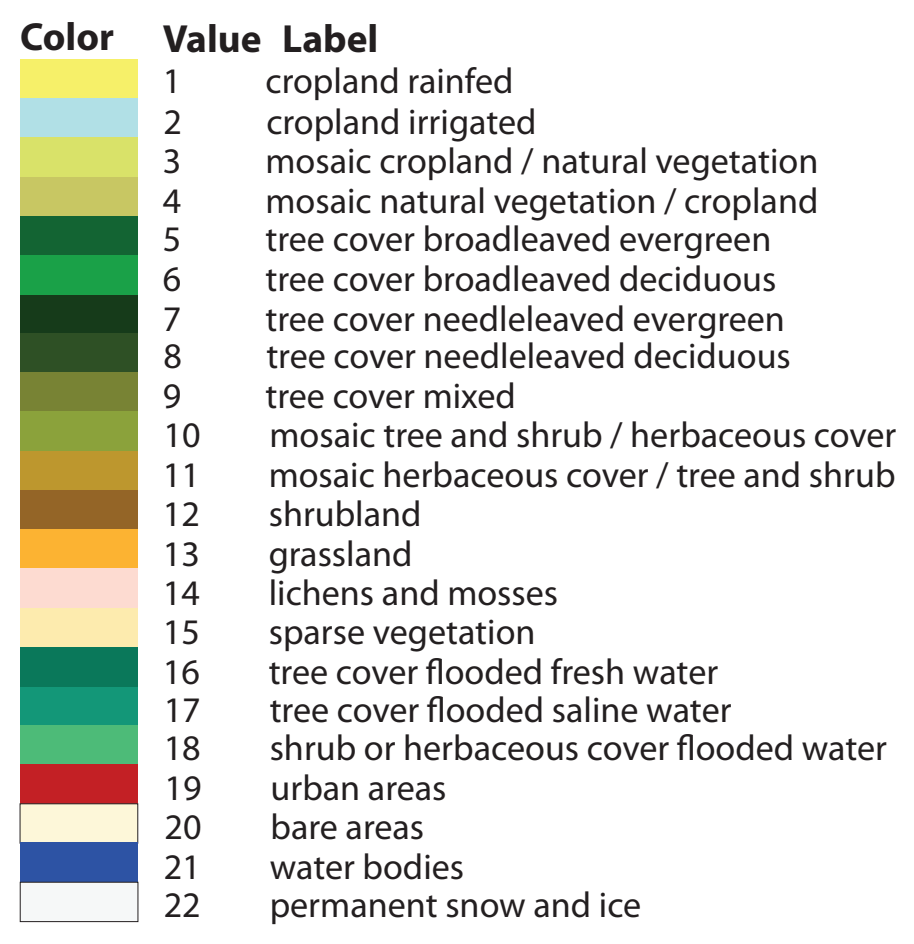

Figure 1: Legend for 22 CCI-LC land cover categories (http://maps.elie.ucl.ac.be/CCI/viewer/) 


\begin{tabular}{cl} 
Color & \multicolumn{2}{l}{ Value Label } \\
1 & alfisols \\
2 & andisols \\
3 & aridisols \\
4 & entisols \\
5 & gelisols \\
6 & histosols \\
7 & inceptisols \\
8 & mollisols \\
9 & oxisols \\
10 & spodosols \\
11 & ultisols \\
12 & vertisols
\end{tabular}

Figure 2: Legend for twelve soil orders. See https://globalrangelands.org/topics/rangelandecology/twelve-soil-orders for description of the orders. 


\section{Color Value Label}

\begin{tabular}{|ll}
1 & very cold, wet \\
2 & very cold, very wet \\
3 & very cold, moist \\
4 & very cold, semi-dry \\
5 & arctic \\
6 & cold, very wet \\
7 & cold, wet \\
8 & cold, moist \\
9 & cold, semi-dry \\
10 & cool, very wet \\
11 & cool, wet \\
12 & cool, moist \\
13 & cool, semi-dry \\
14 & warm, wet \\
15 & warm, very wet \\
16 & cool, dry \\
17 & cold, dry \\
18 & warm, dry \\
19 & warm, semi-dry \\
20 & warm, moist \\
21 & cool, very dry \\
22 & warm, very dry \\
23 & hot, wet \\
24 & hot, moist \\
25 & very cold, dry \\
26 & cold, very dry \\
27 & hot, semi-dry \\
28 & hot, very wet \\
29 & High mountains \\
30 & hot, very dry \\
31 & very hot, very dry \\
32 & very hot, semi-dry \\
33 & very hot, wet \\
34 & very hot, moist \\
35 & very hot, dry \\
36 & very hot, very wet \\
37 & very cold, very dry \\
& \\
\hline
\end{tabular}

Figure 3: Legend for 37 types of bioclimates. See Sayre et al. [2014] 


\begin{tabular}{ll} 
Color & \multicolumn{2}{l}{ Value Label } \\
1 & flat \\
2 & smooth plain with some local relief \\
3 & smooth plain with moderate relief \\
4 & irregular plains with low hills \\
5 & scattered modarate hills \\
6 & moderate hills \\
7 & scattered high hills \\
8 & high hills \\
9 & scattered low mountains \\
10 & low mountains \\
11 & scattered high mountains \\
12 & high mountains \\
13 & tablelands with moderate relief \\
14 & tablelands with considerable relief \\
15 & tablelands with high relief \\
16 & tablelands with very high relief \\
17 & surface water
\end{tabular}

Figure 4: Legend for 17 categories of landfoms. See Karagulle et al. [2017]

\section{References}

Karagulle, D., Frye, C., Sayre, R., Breyer, S., Aniello, P., Vaughan, R., Wright, D., 2017. Modeling global hammond landform regions from 250-m elevation data. Transactions in GIS 21(5), 1040-1060.

Sayre, R., Dangermond, J., Frye, C., Vaughan, R., Aniello, P., Breyer, S., Cribbs, D., Hopkins, D., Nauman, R., Derrenbacher, W., Wright, D., 2014. A new map of global ecological land units - an ecophysiographic stratification approach. Tech. rep., Washington, DC: Association of American Geographers. 